
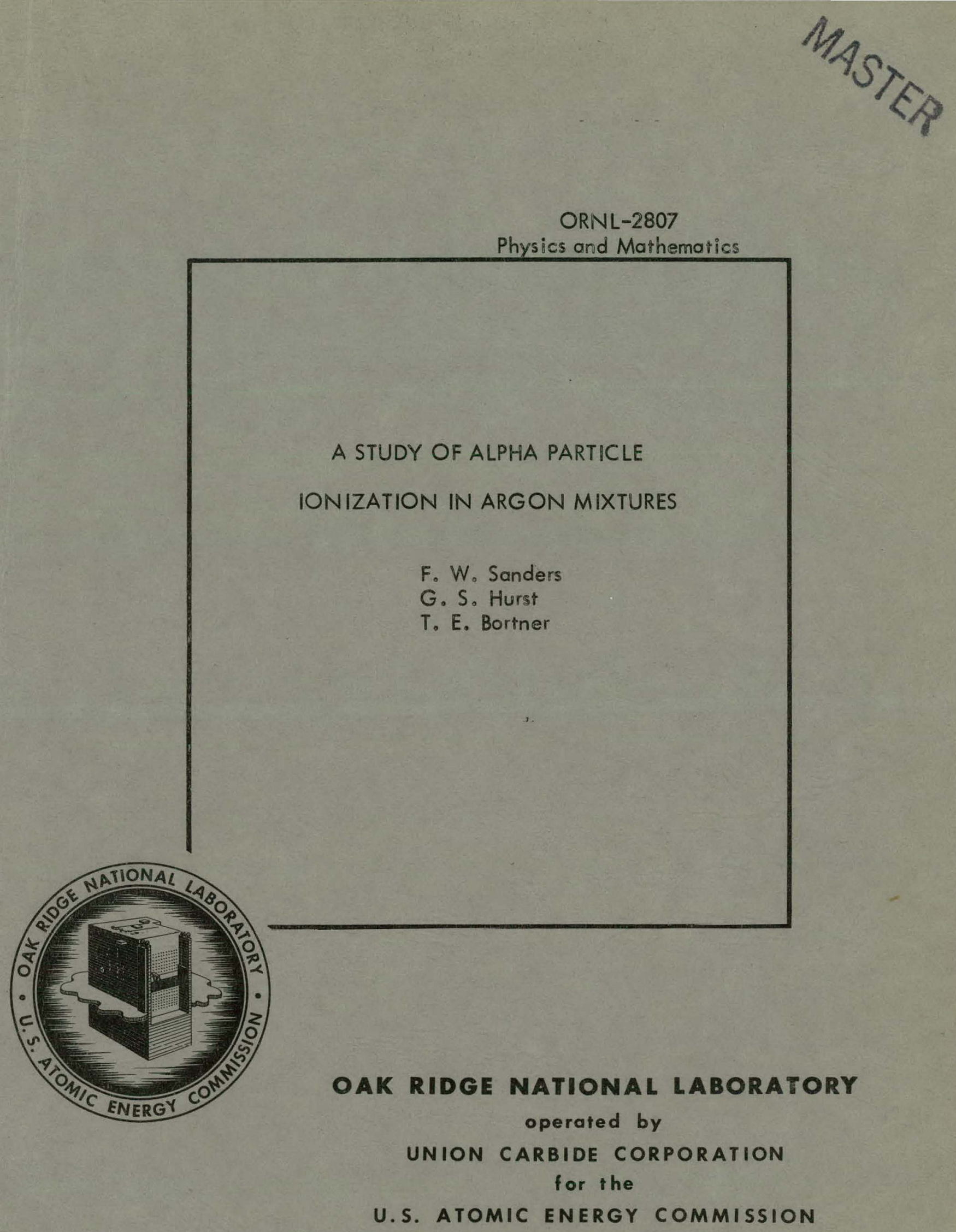


\section{DISCLAIMER}

This report was prepared as an account of work sponsored by an agency of the United States Government. Neither the United States Government nor any agency Thereof, nor any of their employees, makes any warranty, express or implied, or assumes any legal liability or responsibility for the accuracy, completeness, or usefulness of any information, apparatus, product, or process disclosed, or represents that its use would not infringe privately owned rights. Reference herein to any specific commercial product, process, or service by trade name, trademark, manufacturer, or otherwise does not necessarily constitute or imply its endorsement, recommendation, or favoring by the United States Government or any agency thereof. The views and opinions of authors expressed herein do not necessarily state or reflect those of the United States Government or any agency thereof. 


\section{DISCLAIMER}

Portions of this document may be illegible in electronic image products. Images are produced from the best available original document. 
Printed in USA. Price $\$ 1.75$. Available from the

Office of Technical Services

Department of Commerce

Washington 25, D.C.

\section{LEGAL NOTICE}

This report was prepared as an account of Government sponsored work. Neither the United States, nor the Commission, nor any person acting on behalf of the Commission:

A. Makes any warranty or representation, expressed or implied, with respect to the accuracy, completeness, or usefulness of the information contained in this report, or that the use of any information, apparatus, method, or process disclosed in this report may not infringe privately owned rights; or

B. Assumes any liabilities with respect to the use of, or for damages resulting from the use of any information, apparatus, method, or process disclosed in this report.

As used in the above, "person acting on behalf of the Commission" includes any employee or contractor of the Commission, or employee of such confractor, to the extent that such employee or contractor of the Commission, or employed of such contractor prepares, disseminates, or provides access to, any information pursuant to his employment or contract with the Commission, or his employment with such contractor. 
Contract No. W-7405-eng-26

\title{
A STUDY OF ALPHA PARTICLE IONIZATION IN ARGON MIXTURES
}

\author{
F. W. Sanders; G. S. Hurst, and T. E. Bortner \\ HEALTH PHYSICS DIVISION
}

$\begin{array}{r}\text { Date Issued } \\ \text { OCT } 231959 \\ \hline\end{array}$

\footnotetext{
Oak Ridge National Laboratory Operated by Union Carbide Corporation for the

U. S. Atomic Energy Commission Oak Ridge, Tennessee
} 


\section{ACKNOWLEDGMENTS}

The authors wish to express their gratitude to Dr. 1. H. Tipton of the University of Tennessee for aid and equipment used in the spectrographic study; and to Dr. J. L. Magee of the University of Notre Dame and Dr. R. L. Platzman of Purdue University for their helpful comments.

F. W. Sanders, in particular, wishes to extend his appreciation to Dr. E. E. Anderson (ORNL) and to the Oak Ridge Institute of Nuclear Studies which made possible this study under an AEC Radiological Physics Fellowship. 
List of Tables - iv

List of 'Figures. -

1. Introduction -no 1

11. Apparatus - 4

111. Procedure - 11 .

IV. Data

V. Discussion... 38

VI. Conclusion

Bibliography - 53 
1. Average Ion Current Measured as Rate of Charging: a Capacitor Versus Pressure for Several Gases

11. Ionization of Argon Impurity Mixtures Expressed as Per Cent Higher than Ionization of Pure Argon (Per Cent Lower for N I trogen)

111. Total Relative Error of Data for Varjous :Gases and Pressures

IV. Effect on the Film Density of Several Lines of the Emission Spectrum of Argon by the Addition of $3 \%$ Ethane - 


\section{LIST OF FIGURES}

Page

1. Block Diagram of the Apparatus for Measuring $W$ for Alpha Particles ...- 5

2. B lock Diagram of the Gas System 6

3. Diagram of Exposure Chamber

4. Ionization Versus. Plate Voltage for $97 \%$ Argon-3\% Ethane Mixture at $750 \mathrm{~mm} . \mathrm{Hg}$ Pressure

5. Breakdown Voltage Versus Pressure of $97 \%$ Argon-3\% Ethane Mixture

6. Ionization Versus Pressure of Argon and $97 \%$ Argon-3\% Ethane Mixture -..- 25

7. Ionization Versus Pressure of Argon and $99 \%$ Argon-1\% Ethane Mixture

8. Ionization Versus Pressure of Argon and $97 \%$ Argon-3\% Propane

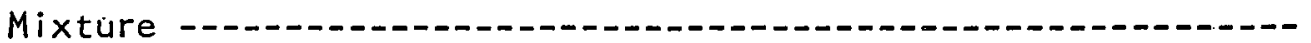

9. Ionization Versus Pressure of Argon and $97 \%$ Argon$3 \% \mathrm{Nitrogen} \mathrm{Mixture} \mathrm{-..28}$

10. Ionization Versus Pressure of Argon and $99.5 \%$ Argon$0.5 \%$ Acetylene Mixture

11. Rate of Change of Rate of Charge Versus Pressure for Argon and $97 \%$ Argon-3\% Ethane Mixture

12. Calculated and Experimental Values of $W$ as a Function of Gas Composition 


\section{INTRODUCTION}

When an alpha particle passes through a gas it may form an ion by acting on atoms or molecules of the gas with enough force to remove an electron. The value of $w$, which is the average energy required to produce an ion pair, is found to be greater than the lowest ionization potential of a given gas. The reason for this is that the energy considered in calculating $W$ goes not only into lonization but also into excitation of non-ionized atoms or molecules and into kinetic energy of the electrons removed in lonization.

The addition of certain impurities to some of the noble gases reduces the value of $W$ cons $I$ derably $l$ and the results of separate additions to argon of seventeen gases have been measured. ${ }^{2}$ These gases have a. range of ionization potentials from 8.5 to 15.7 electron volts (ev). The Ionization potential of argon is $15.68 \mathrm{ev}$. Included were gases with ionization potentials above and below the known metastable excited state of argon, $11.5 \mathrm{ev.} \mathrm{Many} \mathrm{observers} \mathrm{had} \mathrm{believed} \mathrm{that} \mathrm{the} \mathrm{reduction} \mathrm{of} W$, or increased ionization, was caused by the discharge of the metastable state; however, the increased ionization effect was observed using impurities with ionization potentials above the metastable level. The highest ionization potential at which the effect was noted was 14.5 ev;

1 T. E. Bortner and G. S. Hurst, Phys. Rev. 90, 160 (1953).

2 .C. E. Melton, 'Measurement of Ionization Produced by 5-Mev Alpha Particles in Argon Mixtures," A Thesis, Vanderbilt University (February 1954). 
with an impurity having an ionization potential of 15.5 ev there was no increase detected.

This study was undertaken to investigate the cause of the increased ionization in mixtures of argon and impurities with ionization potentials above the argon metastable level, $11.5 \mathrm{ev}$.

Three mechanisms for the increase of ionization by impurities with ionization potentials in the 11.5 to $14.5 \mathrm{ev}$ range have been suggested. The increase could be due to (1) the discharge of a metastable excited level of molecular argon, (2) the action of subexcitation ${ }^{3}$ electrons, i.e. electrons with kinetic energy less than the lowest excited level of argon, or (3) the discharge of a long lived excited state of atomic argon with an energy level greater than $14.5 \mathrm{ev}$. Experiments were undertaken to determine which, if any, of these suggested mechanisms accounts for the increased ionization.

If molecular argon exists, its concentration and therefore its effect on ionization will depend on the pressure of the gas. The effect of a $725 \mathrm{~mm}$ of $\mathrm{Hg}$ change of gas pressure on the increased ionization was studied using a large parallel plate ionization chamber containing a $\mathrm{Pu}^{239}$ alpha source.

The energy distribution of subexcitation electrons, and therefore their effect on the ionization process, is altered by changing $E / P$ (the ratio of change of potential per unit distance to pressure in volts/cm/ $\mathrm{mm} \mathrm{Hg}) .^{3}$ The effects of large changes of $E / P$ were studied in the

3 R. L. Platzman, Rad. Res. 2, 1 (1955). 
ionization chamber.

An optical spectrograph was used in conjunction with ionization chamber data to study the possibility of a long lived excited state of atomic argon. The emission spectrum of pure argon was compared to the spectra of mixtures of argon and ethane, propane, acetylene, and nitrogen. This parallel study was based on the assumption that the same events of interest-occur in the ionization chamber and in the exposire chamber of the spectrograph. 


\section{APPARATUS}

The apparatus might be divided into two categories: that for the study of the effect of changes of $E / P$ and gas pressure on ionization, and that for the study of the effects of impurities on the emission spectrum of argon.

\section{Apparatus for Ionization Study}

The apparatus used for the ionization versus pressure and the ionization versus voltage studies consisted of a large ionization chamber with an uncollimated internal $\mathrm{Pu}^{239}$ alpha source and associated vacuum system, a high voltage supply, a potentiometer, a capacitor and a vibrating reed electrometer.

The parallel plate ionization chamber (Fig。1) was enclosed in a steel cylinder $50 \mathrm{~cm}$ in diameter and $15 \mathrm{~cm}$ high. The $24 \mathrm{~S}$ aluminum plates were. supported $9 \mathrm{~cm}$ apart by Teflon insulators. The collecting plate was $25 \mathrm{~cm}$ in diameter and was surrounded by a guard ring with a clearance of $0.030 \mathrm{~cm}$. The high voltage plate, which contained the $\mathrm{Pu}^{239}$ alpha source flush mounted in its center, was $46 \mathrm{~cm}$ in diameter. The remainder of the gas system (Fig. 2) consisted of two vacuumpressure gauges, a Hastings vacuum gauge, two Wallace and Tiernan vacuum gauges, three mechanical pumps, two diffusion pumps, and two cold traps. One of the Wallace and Tiernan gauges had a range of 0 to $200 \mathrm{~mm}$ of $\mathrm{Hg}$, and the other a range of 0 to $800 \mathrm{~mm}$ of $\mathrm{Hg}$. The diffusion pumps 
UNCL ASSIFIED

OR NL-.LR-DWG. 193

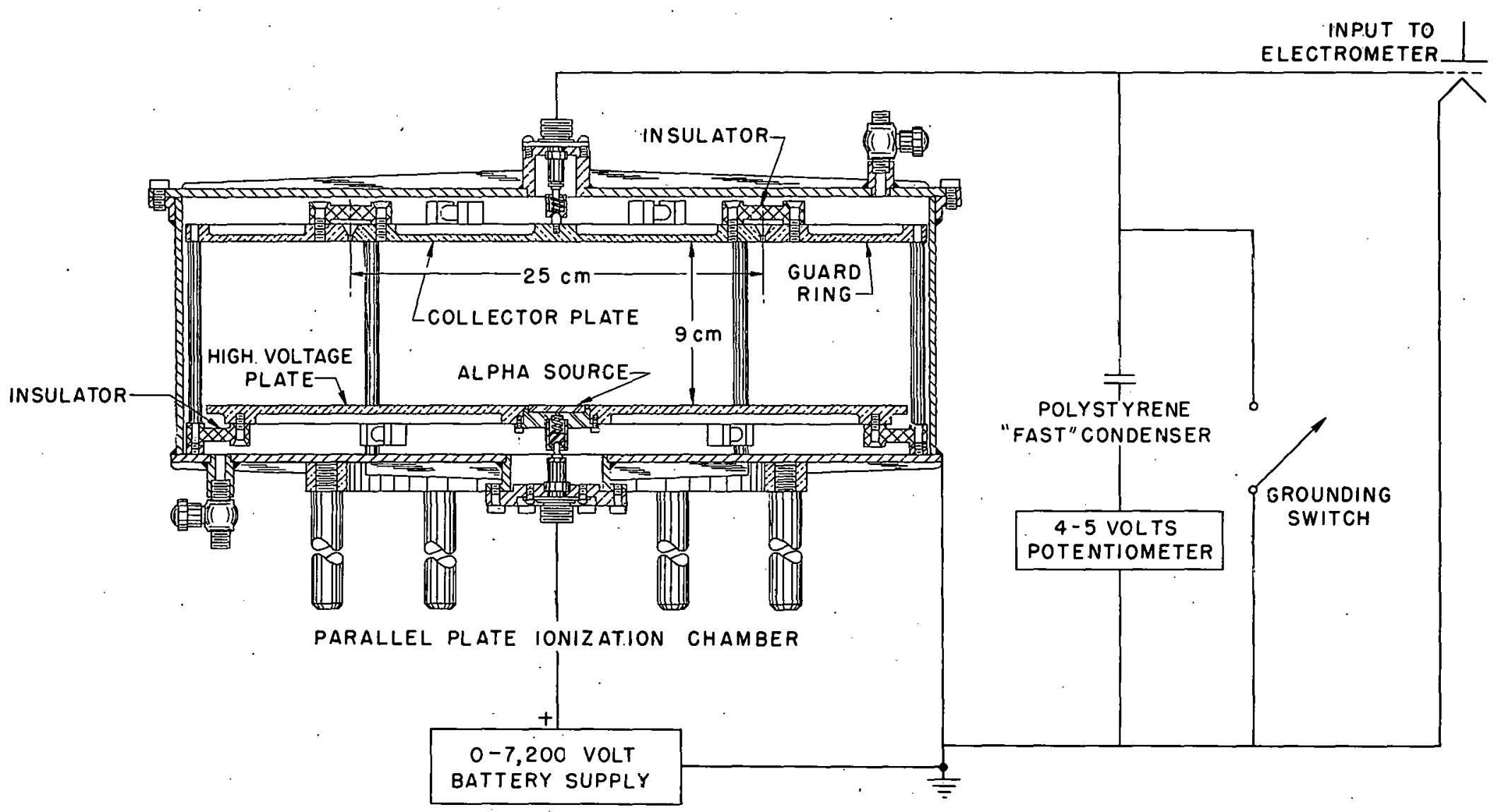

FIG. 1. BLOCK DIAGRAM OF THE APPARATUS FOR MEASURING W FOR ALPHA PARTICLES 
UNCLASSIFIEO

ORNL-LR-OWG. 38545

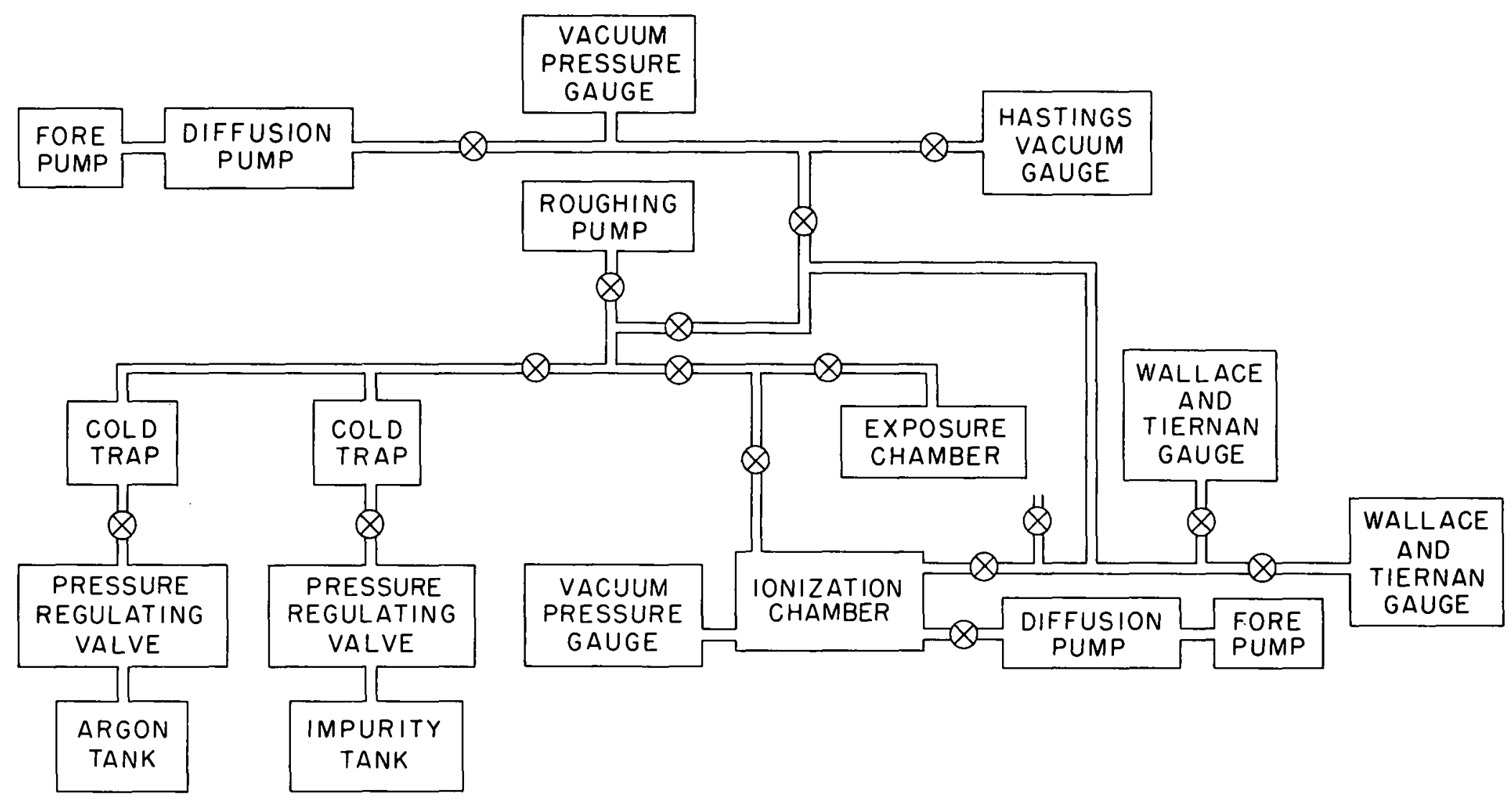

FIG. 2. BLOCK DIAGRAM OF THE GAS SYSTEM 
were VFM model 260, oil diffusion pumps manufactured by $D$ is tillation Products Corporation. The mechanical pumps were Welch Duo-Seal, two of which were used as forepumps in series with the diffusion pumps and one of which was used as a by-pass pump to allow removal of gases that might contain oxygen which would oxidize hot diffusion pump oil. The cold traps were brass cylinders $4.5 \mathrm{~cm}$ in diameter and $16.5 \mathrm{~cm}$ in height. With the exception of the connections to the diffusion pumps, where one inch and three-fourths inch nickel tubing was used, the components of the system were connected with one-fourth inch copper tubing.

Two high voltage supplies were used. For potentials greater than 300 volts a supply consisting of series connected 300 , volt batteries was used. The high voltage plate was connected to the series" positive terminal and the desired voltage was obtained by connecting the ground lead to the negative terminal of the proper battery. For potentials less than 300 volts, a stable regulated high voltage supply manufactured by the Oregon Electric Company was used.

The potentiometer, which was designed for use with this equipment by the Instrument Department of the Oak Ridge National Laboratory, had a reference voltage output that was variable from 0 to 4500 millivolts. It was monitored at five points with a Rubicon potentiometer.

A "Fast" capacitor manufactured by John E. Fast Company was used as the collecting capacitor.

An Applied Physics Corporation model 30 vibrating reed electrometer was used as a null indicator. The instrument had a background drift 
rate of less than one millivolt per minute which was negligible compared to the signal drift rate.

\section{Apparatus for Spectrum Study}

The apparatus used for studying the effect of impurities in argon on the emission spectrum of argon consisted of a gas mixing and filling system, an exposure chamber, a spark source, a spectrograph, film and a recording microphotometer.

The gas system and ionization chamber previously described were used for preparing gas mixtures and filling the exposure chamber. This system was used because it was convenient and because its large capacity enhanced the accuracy of the admlxing of a small percentage of impurity. The exposure chamber could be connected directly to this system.

The exposure chamber (FIg. 3) consisted of a pipe tee of $6.3 \mathrm{~cm}$ inside diameter. The opposed openings were fitted with Teflon plugs which supported screw advancing electrode holders. The distance between the electrodes could be adjusted while a gas sample was in the chamber. The electrodes, which were of spectroscopically pure magnesium, were maintained $8 \mathrm{~mm}$ apart during operation. The third opening had a Teflon plug fitted with a quartz window $2.5 \mathrm{~cm}$ in diameter and $3 \mathrm{~mm}$ thick.

The spark source was manufactured by Applied Research LaboratoriesHenry W. Dietart Company. It was used at a power level of 2 KVA and was connected by cables to the electrode holders of the exposure chamber.

A Bausch and Lomb 1,5 meter stigmatic grating spectrograph was used. The dispersion of this instrument was $15 \AA / \mathrm{mm}$ in the first order 


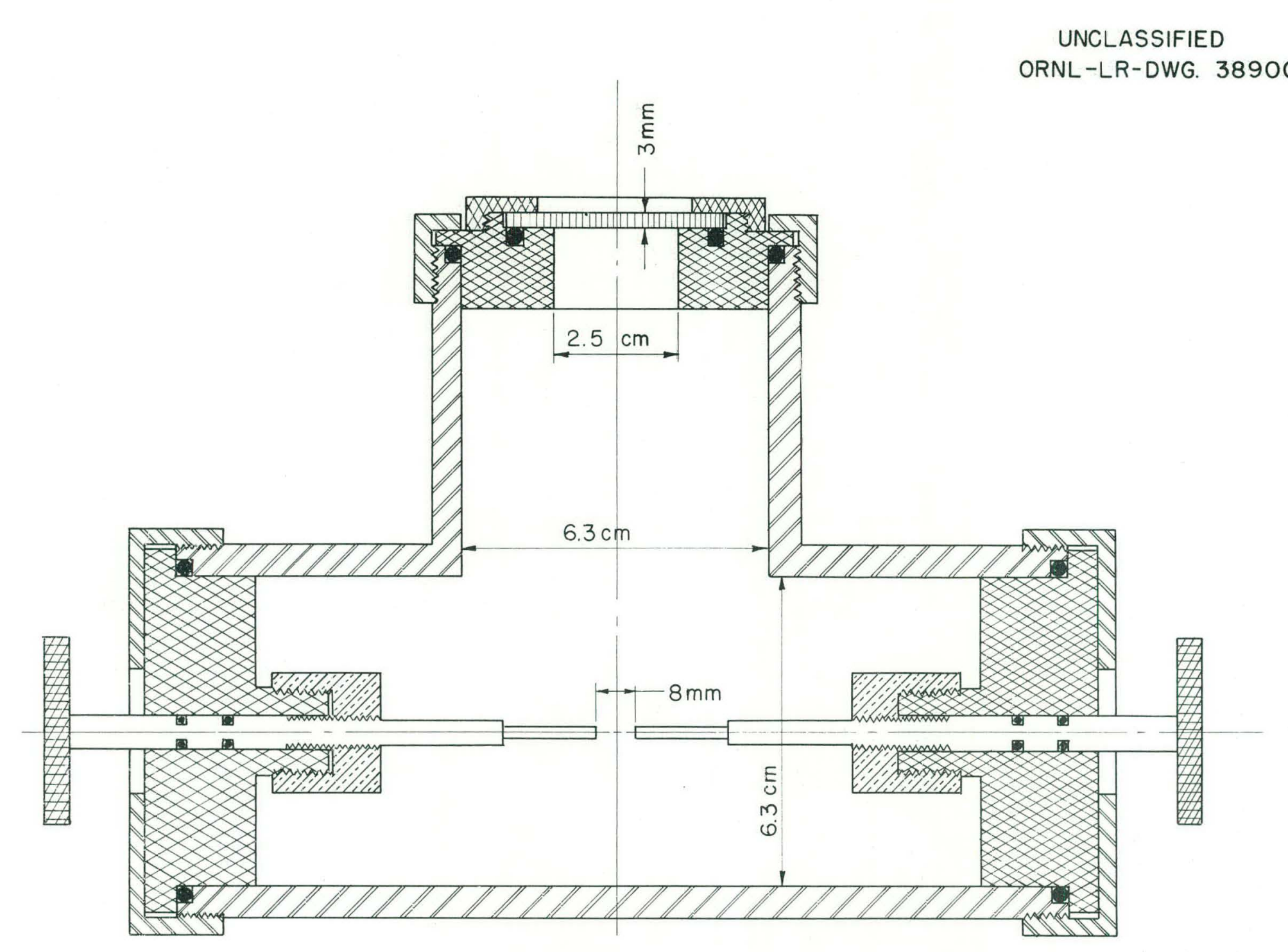

FIG. 3. DIAGRAM OF EXPOSURE CHAMBER 
and $7.5 \AA / \mathrm{mm}$ in the second order. Eastman Spectrographic Safety Film, type $1-L$, which covers the visible range plus the near ultraviolet, was used in the spectrograph. The recording microphotometer used was a Leeds and Northrup model 6700-Al, with a Speedomax recorder. 


\section{PROCEDURE}

In order to remove impurities, especially water vapor, all gases studied were purified by flowing slowly through a dry ice cold trap. Argon purified in th is manner showed a purity of $99.9 \%$ when analyzed with a mass spectrograph. Prior to filling, the entire gas system was flushed with argon and pumped to a pressure of less than $10^{-3} \mathrm{~mm}$ of $\mathrm{Hg}$, the smallest unit registered by the Hastings vacuum gauge used. All fillings were made to a pressure of $750 \mathrm{~mm}$ of $\mathrm{Hg}$. When pure argon was used, the chamber was flushed for ten minutes and then pumped to $750 \mathrm{~mm}$ of $\mathrm{Hg}$ and sealed. When a mixture of gases was used, argon was admitted to the proper partial pressure, the chamber sealed, the remainder of the system evacuated and flushed three times with the correct impurity, and the impurity was then admitted to the chamber to complete the $750 \mathrm{~mm}$ of: $\mathrm{Hg}$ total pressure. Impurities used included ethane $\left(\mathrm{C}_{2} \mathrm{H}_{6}\right)$, propane $\left(\mathrm{C}_{3} \mathrm{H}_{8}\right)$, acetylene $\left(\mathrm{C}_{2} \mathrm{H}_{2}\right)$, and nitrogen $\left(\mathrm{N}_{2}\right)$. The percentages of impurity ${ }^{2}$ used were those which gave the greatest lowering of $W$ except those for nitrogen, which showed no lowering effect, and for one series of argon-ethane measurements. Percentages used were: ethane, $3 \%$ and $1 \%$; propane, 3\%; nitrogen, 3\%; and acetylene, $0.5 \%$. Maximum lowering of $w$ for argon-ethane is at $3 \%$ ethane.

To insure complete collection of the ions formed, saturation curves (Fig. 4) were determined at $750 \mathrm{~mm}$ of $\mathrm{Hg}$ pressure for each gas mixture to be tested and for pure argon. In all cases saturation occurred below 300 volts. For this chamber the number of ions collected at voltages 


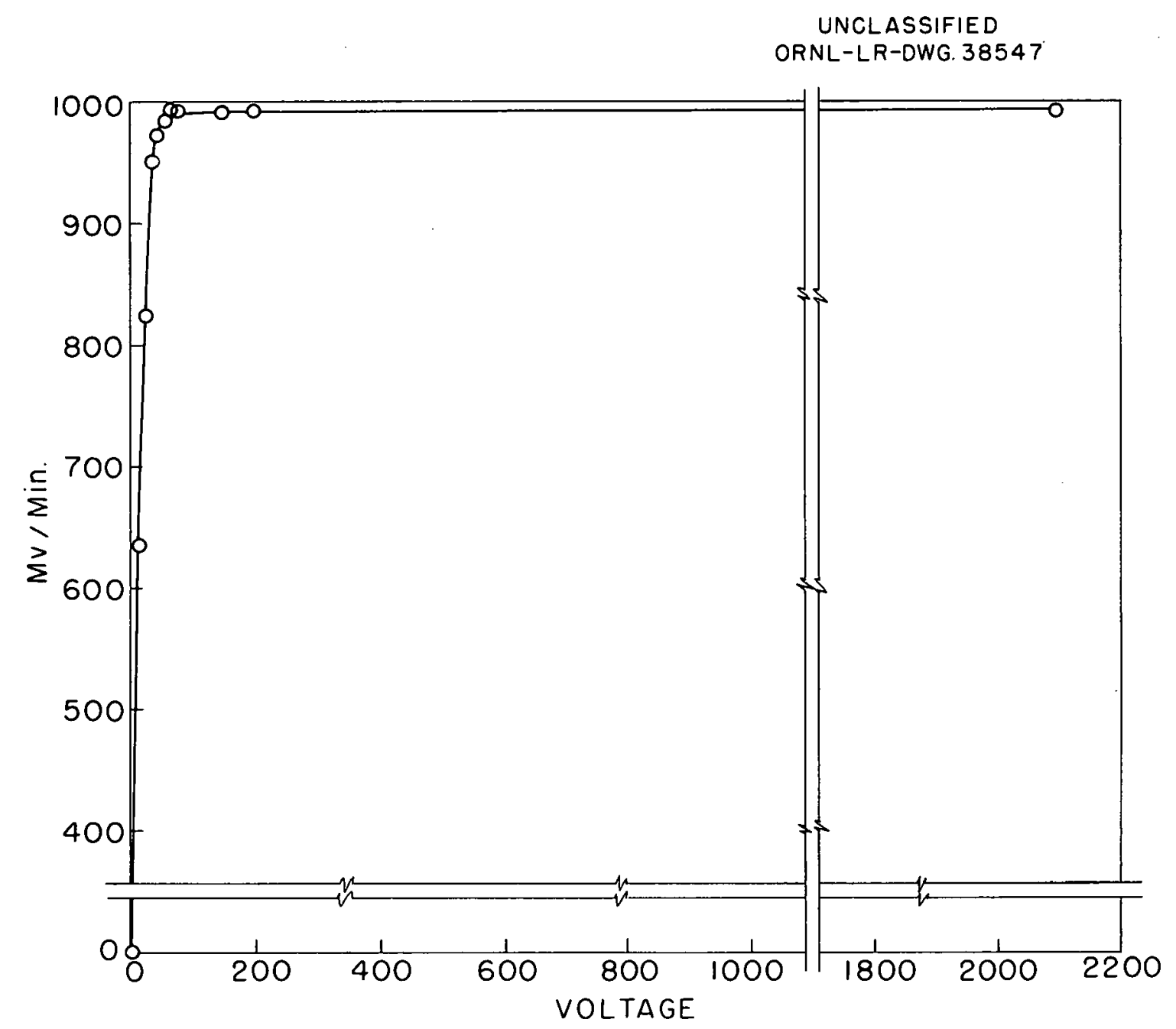

FIG. 4. IONIZATION VERSUS PLATE VOLTAGE FOR $97 \%$ ARGON-3\% ETHANE MIXTURE AT $750 \mathrm{~mm} \mathrm{Hg}$ PRESSURE 
above the saturation voltage was constant up to the potential at which high voltage breakdown occurred. At this potential, measurements could no longer be made because of obvious fluctuations of the electrometer. Voltage used at $750 \mathrm{~mm}$ of $\mathrm{Hg}$ pressure was 2100 volts.

Because the potential at which high voltage discharge starts becomes much lower at lowered pressure a chamber of each gas mixture was: slowly pumped down until the discharge started. The pressure above which that voltage could be safely used was noted (Fig. 5), the voltage was. lowered 300 volts, and the pump down was continued. This calibration insured that the voltage used was always well above the saturation and below the discharge potential.,

The final measurements were made at gas pressures which ranged stepwise from $750 \mathrm{~mm}$ of $\mathrm{Hg}$ to $10 \mathrm{~mm}$ of $\mathrm{Hg}$. The variable measured was the length of time required to charge the capacitor to a predetermined voltage.

A formula for determining $W$ can be derived easily by using the following notation:

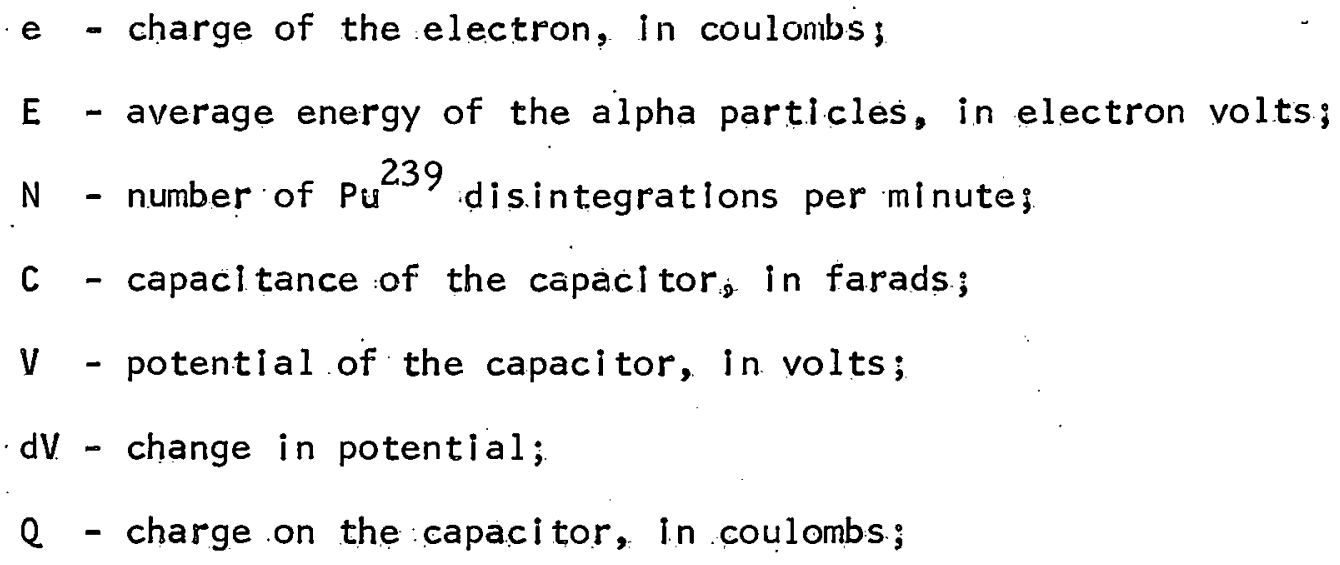


UNCLASSIFIED

ORNL-LR-DWG. 38548

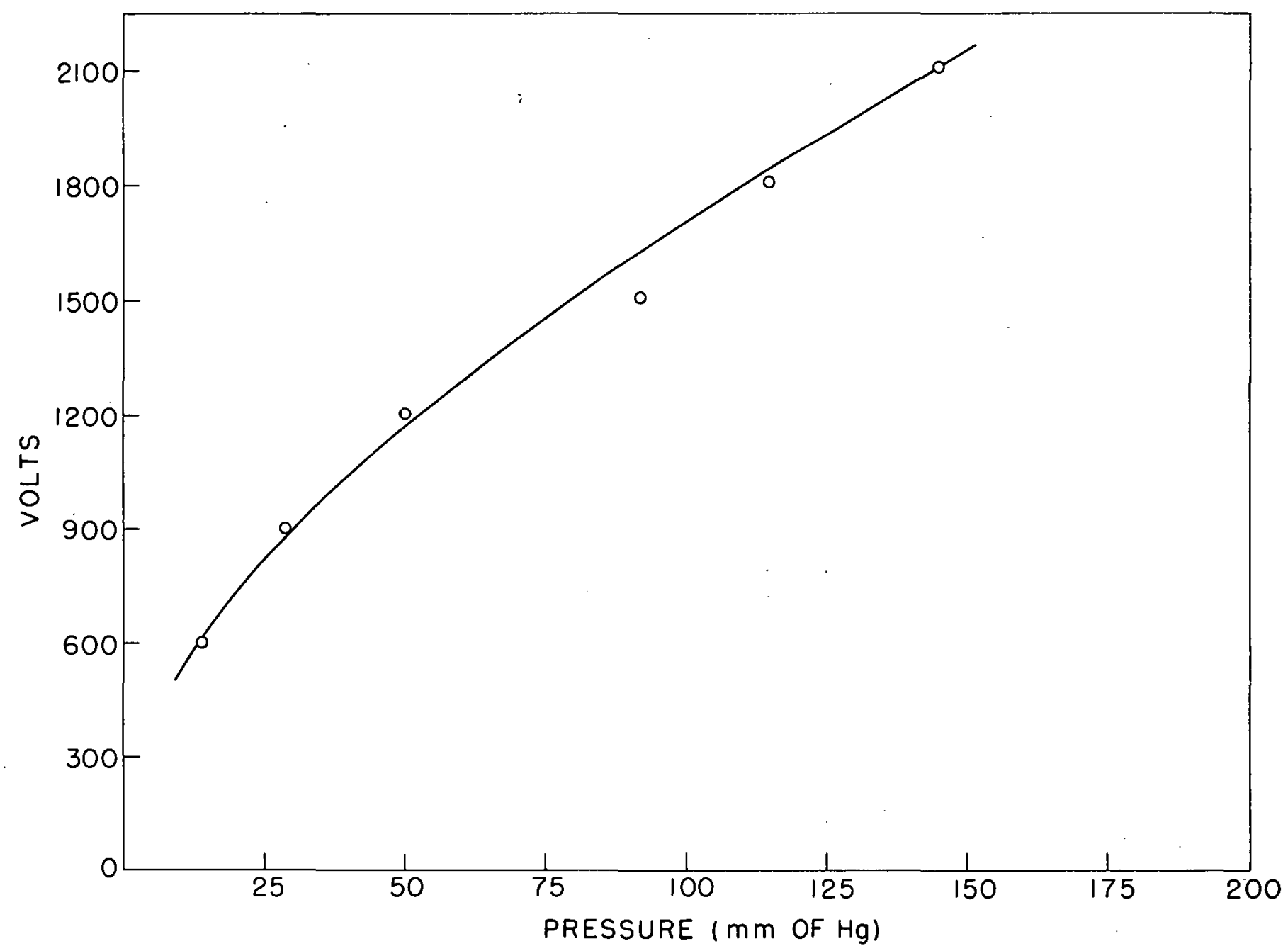

FIG. 5. BREAKDOWN VOLTAGE VERSUS PRESSURE OF $97 \%$ ARGON-3\% ETHANE MIXTURE. 


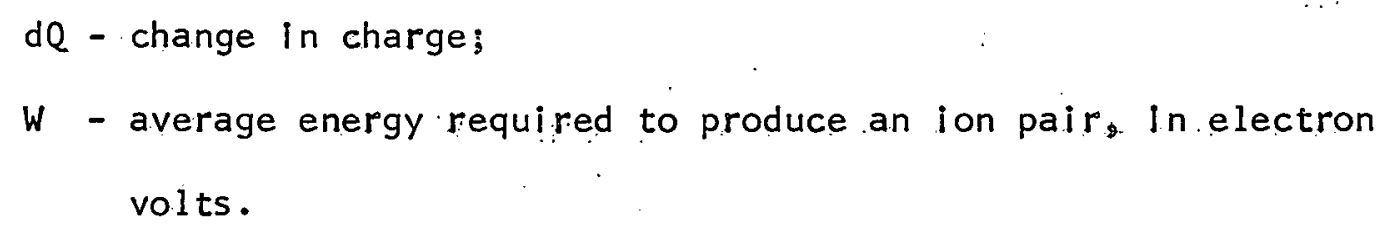
volts.

The total energy loss per minute of the alpha particles in the gas is NE.

$$
Q=C V
$$

so the rate of change of charge on the capacitor. is

$$
\frac{d Q}{d t}=C \frac{d V}{d t}
$$

With $\mathrm{dV} / \mathrm{dt}$ expressed in volts per minute the rate of ion palir production is

$$
\frac{\text { ion pairs }}{\text { minute }}=\frac{C d V}{e d t}
$$

Since

$$
W=\frac{\text { energy expended }}{\text { ion pairs produced }}
$$


then

$$
W=\frac{N E e}{C(d V / d t)}
$$

and since $e, E, C$, and $N$ were constant throughout the experiment,

$$
W=\frac{k}{d V / d t}
$$

or

$$
\frac{d V}{d t}=\frac{k}{w}
$$

Since in this study only relative $W^{\prime}$ s were needed it was much more convenient to compare the $d V / d t$ values, in millivolts per minute. Curves were obtained showing the rate of change of charge on the capacitor versus the gas pressure. The argon data were compared, point for point, to the mixture data and the relative changes due to the impurities were calculated. The final data for argon and for each mixture are the averages of three separate determinations in each case.

In preparation for the spectrographic investigation the gas exposure chamber was connected to the gas system, pumped down, flushed three times with pure argon, pumped down again, and then opened to the ionization chamber. The gases, either pure argon or mixtures, were admitted to the ionization chamber in the manner previously described. 
The exposure chamber was sealed at:750 $\mathrm{mm}$ of $\mathrm{Hg}$ and disconnected. it was then placed in a holder on the optical bench of the spectrograph. All exposures were made from the same holder: and chamber position. The spark source was connected by cables to the exposure chamber electrode holders and operated for an automatically timed ten seconds. . Without moving the film holder, the exposure chamber was removed, refilled and replaced, and another exposure was made. Three exposures were made on each film, one of pure argon and two separate mixings of the argonimpurity mixture. Each exposure used a band of film $2 \mathrm{~mm}$ wide. on a few films an additional band was exposed to a.Hg vapor discharge tube.

The films were developed for three minutes in Kodak D-19 developer, placed in Kodak stop bath SB-5 for one minute,, transferred to Kodak fixer F-5 for fifteen minutes, washed in cool running water for ten minutes, run through a Kodak Photo-Flo bath for thirty seconds, and then hung up to dry.

After drying, films:were placed between two glass plates on the microphotometer film carriage. The microphotometer was then used to make a graphic representation on a paper tape of the density of the spectral lines on the film. The Hg spectrum was added to the film to be used as a standard, as $\mathrm{Hg}$ has a relatively simple and easily identifiable emission spectrum. ${ }^{4}$ The argon lines were identified by comparison with

4 Handbook of Chemistry and Physics, Chemical Rubber Publișting Co., Cleveland (1957-1958). 
the Handbook values for $\mathrm{Hg}$ and by interpolation.

Each tape which represented the spectrum of a gas mixture was compared to the tape which represented the pure argon spectrum from the same film. This procedure eliminated errors which could be caused by slight varlation in developing, placing of the film in the film carriage and focussing the microphotometer lenses. The tapes for the mixtures were compared, line by line, to the tapes for pure argon. Lines for which the film density was greatly reduced by the addition of the impurity were identified by wave length, and the electron transitions by which the argon atom emits these lines were determined. ${ }^{5,6}$ The atomic energy level at the start of each transition was then determined. ${ }^{7}$ To convert these levels into electron volts, the following method was used:

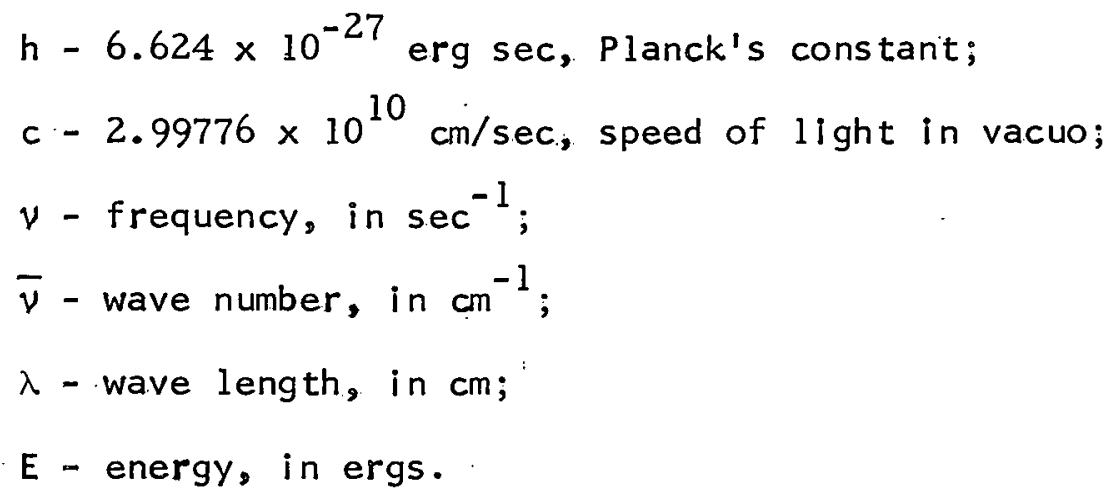

5 K. W. Meissner, Zeit. Phys. 39, 172 (1926); $\underline{40}, 839$ (1927).

6 J. B. Green and B. Fried, Phys. Rev. 54, 876 (1938).

7 Atomic Energy Levels, Circular 467, U. S. Dept. of Commerce, National Bureau of : Standards (1949). 
From the relationships,

$$
\nu=\frac{c}{\lambda}
$$

and

$$
\begin{gathered}
\bar{\nu}=\frac{1}{\lambda} \\
\nu=\bar{\nu} c
\end{gathered}
$$

as

$$
E=h \nu
$$

Then

$$
E=\bar{\nu} \text { ch }
$$

This gives the energy in ergs. Dividing $E$ by $1.602 \times 10^{-12}$ ergs/ev converts energy to electron volts. The wave number is the difference between the atomic energy level at the start and at the end of the transition. 


\section{DATA}

\section{Data from the Ionization Study}

The ionization as a function of absolute pressure was measured three times for each of the gases used. These gases included: $97 \%$ argon-3\% ethane; $99 \%$ argon- $1 \%$ ethane; $97 \%$ argon-3\% propane; $97 \%$ argon-3\% nitrogen; 99.5\% argon-0.5\% acetylene; and pure argon. The ion current values for the three determinations at each pressure were averaged (Table 1). The maximum deviations from the average values were as follows: for the argon-propane and the $97 \%$ argon-3\% ethane mixtures, $0.75 \%$; for the $99 \%$ argon- $1 \%$ ethane mixture, $0.6 \%$; for the argon-nitrogen and argonacetylene mixtures, $0.5 \%$; and for pure argon, $1.7 \%$. The average value for each mixture was then compared to the average value for pure argon for each pressure and the percentage of difference was calculated (Table 11). For the $97 \%$ argon-3\% ethane, the $99 \%$ argon- $1 \%$ ethane, and the $97 \%$ argon-3\% propane mixtures, ionization versus pressure curves (Figs。 $6,7,8$ ) are. similar in shape to the pure argon curve with which each is plotted. The argon-nitrogen data (Fig. 9) show no increase of ionization, as was expected. $^{2}$ The argon-acetylene curve (Fig. 10) is slightly different because the ionization current starts to decrease at a slightly higher pressure than for any other mixture or gas used. It should be noted that the ionization potential of propane $(11.2 \mathrm{ev})^{2}$ is well below; the ionization potential of acetylene $(11.45 \mathrm{ev})^{2}$ is slightly below; and the ionization potential of ethane $(12.8 \mathrm{ev})^{4}$ is well above the metastable level of argon $(11.5 \mathrm{ev})$. The ionization potential of molecular nitrogen 


\section{Table I}

Average Ion Current Measured as Rate of Charging a Capacitor Versus Pressure for Several Gases

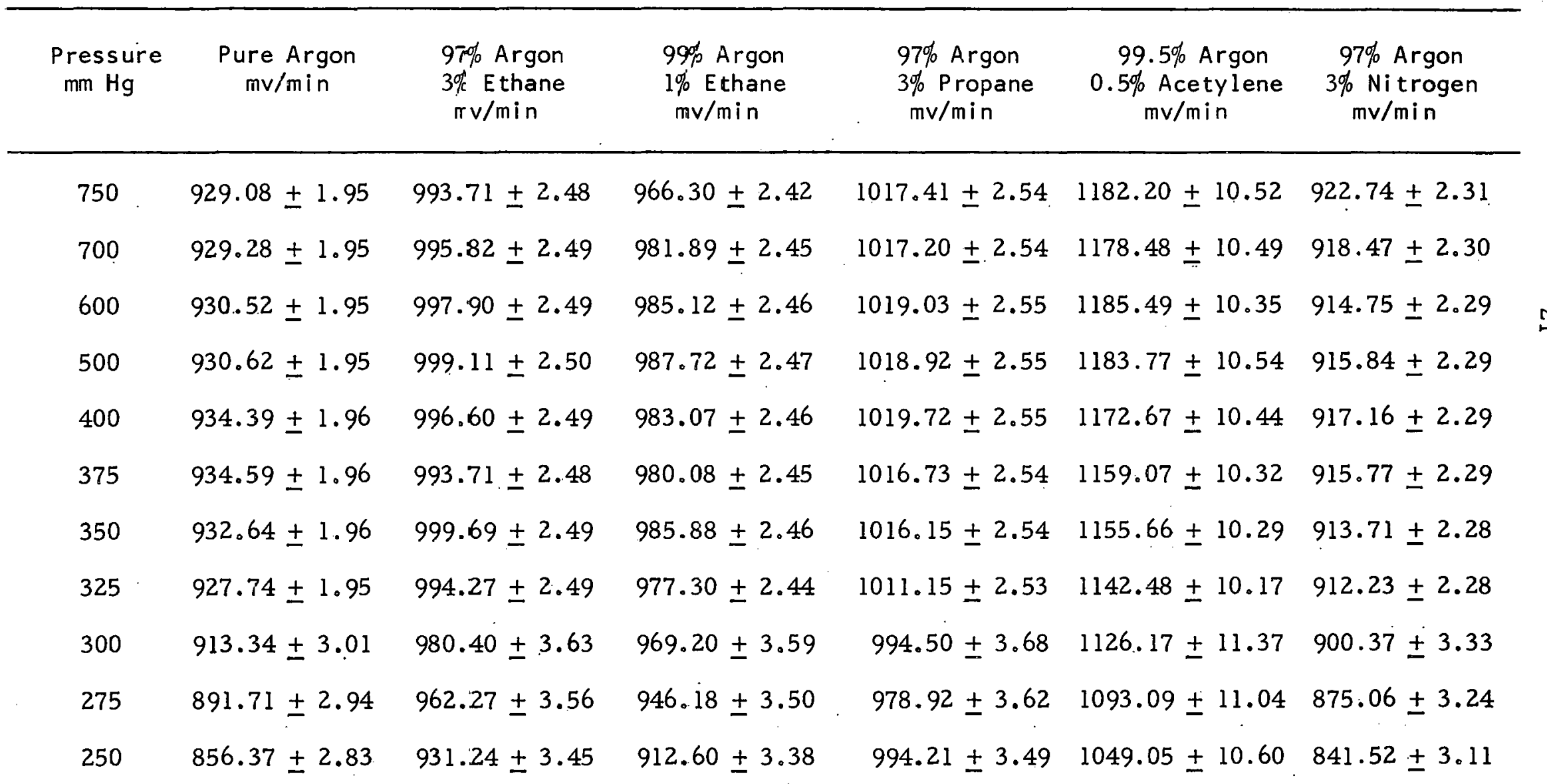




\section{Table I (continued)}

Average Ion Current Measured as Rate of Charging a Capacitor Versus. Pressure for Several Gases

\begin{tabular}{|c|c|c|c|c|c|c|}
\hline $\begin{array}{l}\text { Pressure } \\
\mathrm{mm} \mathrm{Hg}\end{array}$ & $\begin{array}{c}\text { Pure Argon } \\
\mathrm{mv} / \mathrm{min}\end{array}$ & $\begin{array}{c}97 \% \text { Argon } \\
3 \% \text { Ethane } \\
\mathrm{mv} / \mathrm{min}\end{array}$ & $\begin{array}{l}99 \% \text { Argon } \\
1 \% \text { Ethane } \\
\mathrm{mv} / \mathrm{min}\end{array}$ & $\begin{array}{c}97 \% \text { Argon } \\
3 \% \text { Propane } \\
\mathrm{mv} / \mathrm{min}\end{array}$ & $\begin{array}{c}99.5 \% \text { Argon } \\
0.5 \% \text { Acetylene } \\
\mathrm{mv} / \mathrm{min}\end{array}$ & $\begin{array}{c}97 \% \text { Argon } \\
3 \% \mathrm{Nitrogen} . \\
\mathrm{mv} / \mathrm{min}\end{array}$ \\
\hline 225 & $784.31 \pm 2.59$ & $873.96 \pm 3.23$ & $850.82 \pm 3.15$ & $879.43 \pm 3.25$ & $969.10 \pm 9.79$ & $772.67 \pm 2.86$ \\
\hline 200 & $675.78 \pm 2.16$ & $769.37 \pm 2.77$ & $747.63 \pm 2.69$ & $764.47 \pm 2.75$ & $827.36 \pm 8.27$ & $665.44 \pm 2.40$ \\
\hline 175 & $578.97 \pm 1.85$ & $633.45 \pm 2.28$ & $614.26 \pm 2.21$ & $649.37 \pm 2.34$ & $710.74 \pm 7.11$ & $571.19 \pm 2.06$ \\
\hline 150 & $477.08 \pm 1.52$ & $518.49 \pm 1.87$ & $503.25 \pm 1.81$ & $531.42 \pm 1.91$ & $582.27 \pm 5.82$ & $467.16 \pm 1.68$ \\
\hline .125 & $385.57 \pm 1.23$ & $414.25 \pm 1.49$ & $402.83 \pm 1.45$ & $429.92 \pm 1.55$ & $467.20 \pm 4.67$ & $383.66 \pm 1.38$ \\
\hline 100 & $300.66 \pm 1.47$ & $319.02 \pm 1.69$ & $306.57 \pm 1.62$ & $335.04 \pm 1.78$ & $362.83 \pm 4.25$ & $295.16 \pm 1.56$ \\
\hline 75 & $218.23 \pm 1.07$ & $235.19 \pm 1.25$ & $227.89 \pm 1.21$ & $241.50 \pm 1.28$ & $262.55 \pm 3.07$ & $214.41 \pm 1.14$ \\
\hline 50 & $143.49 \pm 0.70$ & $152.15 \pm 0.81$ & $148.56 \pm 0.79$ & $157.30 \pm 0.83$ & $173.68 \pm 2.03$ & $140.76 \pm 0.75$ \\
\hline 25 & $70.61 \pm 0.35$ & $74.74 \pm 0.40$ & $73.08 \pm 0.39$ & $77.86 \pm 0.41$ & $85.76 \pm 1.00$ & $71.34 \pm 0.38$ \\
\hline 15 & $44.53 \pm 0.22$ & & $45.14 \pm 0.24$ & $48.76 \pm 0.26$ & $52.73 \pm 0.62$ & $44.39 \pm 0.24$ \\
\hline 10 & $29.56 \pm 0.14$ & & $30.06 \pm 0.16$ & $32.43 \pm 0.17$ & $35.28 \pm 0.41$ & $28.99 \pm 0.15$ \\
\hline
\end{tabular}


Táble 11

!onization of Argon-Impurity Mixtures Expressed as Per Cent Higher than Jonization of Pure Argon (Per Cent Lower for Nitrogen)

\begin{tabular}{lccccc}
\hline $\begin{array}{c}\text { Pressure } \\
\mathrm{mm} \mathrm{Hg}\end{array}$ & $\begin{array}{c}97 \% \text { Argon } \\
3 \% \text { Ethane }\end{array}$ & $\begin{array}{c}99 \% \text { Argon } \\
1 \% \text { Ethane }\end{array}$ & $\begin{array}{c}97 \% \text { Argon } \\
3 \% \text { Propane }\end{array}$ & $\begin{array}{c}99.5 \% \text { Argon } \\
0.5 \% \text { Acetylene }\end{array}$ & $\begin{array}{c}97 \% \text { Argon } \\
3 \% \text { trogen }\end{array}$ \\
\hline 750 & $6.956 \pm 0.493$ & $4.006 \pm 0.479$ & $9.561 \pm 0.503$ & $27.244 \pm 1.399$ & $0.682 \pm 0.460$ \\
700 & $7.160 \pm 0.494$ & $5.661 \pm 0.485$ & $9.461 \pm 0.503$ & $26.816 \pm 1.395$ & $1.164 \pm 0.460$ \\
600 & $7.240 \pm 0.493$ & $5.867 \pm 0.486$ & $9.511 \pm 0.504$ & $27.309 \pm 1.375$ & $1.696 \pm 0.459$ \\
500 & $7.360 \pm 0.494$ & $6.136 \pm 0.488$ & $9.488 \pm 0.503$ & $27.202 \pm 1.399$ & $1.588 \pm 0.459$ \\
400 & $6.658 \pm 0.491$ & $5.210 \pm 0.484$ & $9.132 \pm 0.502$ & $25.501 \pm 1.381$ & $1.844 \pm 0.459$ \\
375 & $6.326 \pm 0.489$ & $4.867 \pm 0.482$ & $8.789 \pm 0.500$ & $24.019 \pm 1.364$ & $2.014 \pm 0.459$ \\
350 & $6.868 \pm 0.492$ & $5.709 \pm 0.486$ & $8.954 \pm 0.501$ & $23.913 \pm 1.364$ & $2.021 \pm 0.457$ \\
325 & $7.170 \pm 0.496$ & $5.342 \pm 0.484$ & $8.991 \pm 0.502$ & $23.147 \pm 1.355$ & $1.672 \pm 0.460$ \\
300 & $7.342 \pm 0.754$ & $6.116 \pm 0.743$ & $8.886 \pm 0.762$ & $23.302 \pm 1.651$ & $1.420 \pm 0.699$ \\
275 & $7.913 \pm 0.757$ & $6.108 \pm 0.742$ & $9.780 \pm 0.768$ & $22.584 \pm 1.642$ & $1.867 \pm 0.699$ \\
250 & $8.743 \pm 0.776$ & $6.566 \pm 0.747$ & $10.024 \pm 0.771$ & $22.383 \pm 1.634$ & $1.734 \pm 0.699$
\end{tabular}


Table $\rfloor$ (continued)

Ionization of Argon-Impurity Mixtures Expressed as Per Cent Higher than Ionization of Pure Argon (Per Cent Lower for Nitrogen)

\begin{tabular}{|c|c|c|c|c|c|}
\hline Pressure & $\begin{array}{l}97 \% \text { Argon } \\
3 \% \text { Ethane }\end{array}$ & $\begin{array}{l}99 \% \text { Argon } \\
1 \% \text { Ethane }\end{array}$ & $\begin{array}{l}\text { 97\% Argon } \\
3 \% \text { Propane }\end{array}$ & $\begin{array}{c}99.5 \% \text { Argon } \\
0.5 \% \text { Acetylene }\end{array}$ & $\begin{array}{l}97 \% \text { Argon } \\
3 \% \text { Nitrogen }\end{array}$ \\
\hline 225 & $11.430 \pm 0.783$ & $8.480 \pm 0.760$ & $12.128 \pm 0.785$ & $23.561 \pm 1.656$ & $1.484 \pm 0.700$ \\
\hline 200 & $13.849 \pm 0.776$ & $10.632 \pm 0.752$ & $13.124 \pm 0.769$ & $22.430 \pm 1.615$ & $1.530 \pm 0.620$ \\
\hline 175 & $9.410 \pm 0.746$ & $6.095 \pm 0.721$ & $12.160 \pm 0.763$ & $22.759 \pm 1.620$ & $1.344 \pm 0.733$ \\
\hline 150 & $8.680 \pm 0.740$ & $6.787 \pm 0.885$ & $11.390 \pm 0.755$ & $22.049 \pm 1.609$ & $2.079 \pm 0.677$ \\
\hline 125 & $7.438 \pm 0.732$ & $4.476 \pm 0.709$ & $11.502 \pm 0.746$ & $21.171 \pm 1.598$ & $0.495 \pm 0.678$ \\
\hline 100 & $6.107 \pm 1.086$ & $1.966 \pm 1.038$ & $11.435 \pm 1.137$ & $21.010 \pm 2.005$ & $1.820 \pm 1.012$ \\
\hline 75 & $7.772 \pm 1.106$ & $4.427 \pm 1.067$ & $10.663 \pm 1.129$ & $20.309 \pm 1.997$ & $1.750 \pm 1.021$ \\
\hline 50 & $6.035 \pm 1.087$ & $3.533 \pm 1.056$ & $9.624 \pm 1.113$ & $21.046 \pm 2.006$ & $1.903 \pm 1.020$ \\
\hline 25 & $5.849 \pm 1.097$ & $3.498 \pm 1.065$ & $10.268 \pm 1.127$ & $21.456 \pm 2.018$ & $-0.103 \pm 0.104$ \\
\hline 15 & & $3.699 \pm 2.808$ & $9.499 \pm 1.125$ & $18.415 \pm 1.977$ & $0.314 \pm 1.033$ \\
\hline 10 & & $1.691 \pm 1.023$ & $9.709 \pm 1.095$ & $19.350 \pm 1.952$ & $1.928 \pm 0.990$ \\
\hline
\end{tabular}




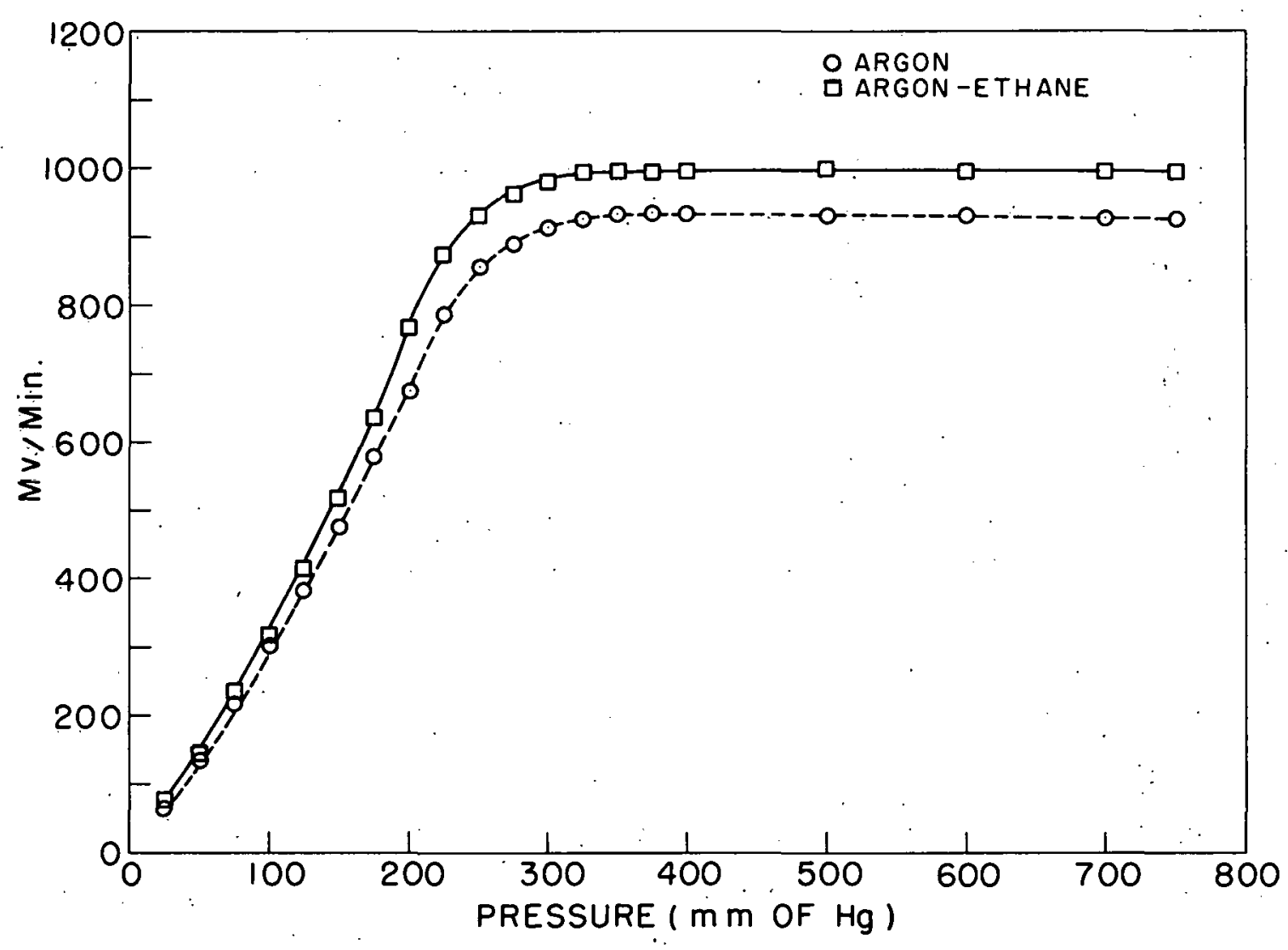

FIG. 6. IONIZATION VERSUS PRESSURE OF ARGON AND 97\% ARGON-3\% ETHANE MIXTURE 


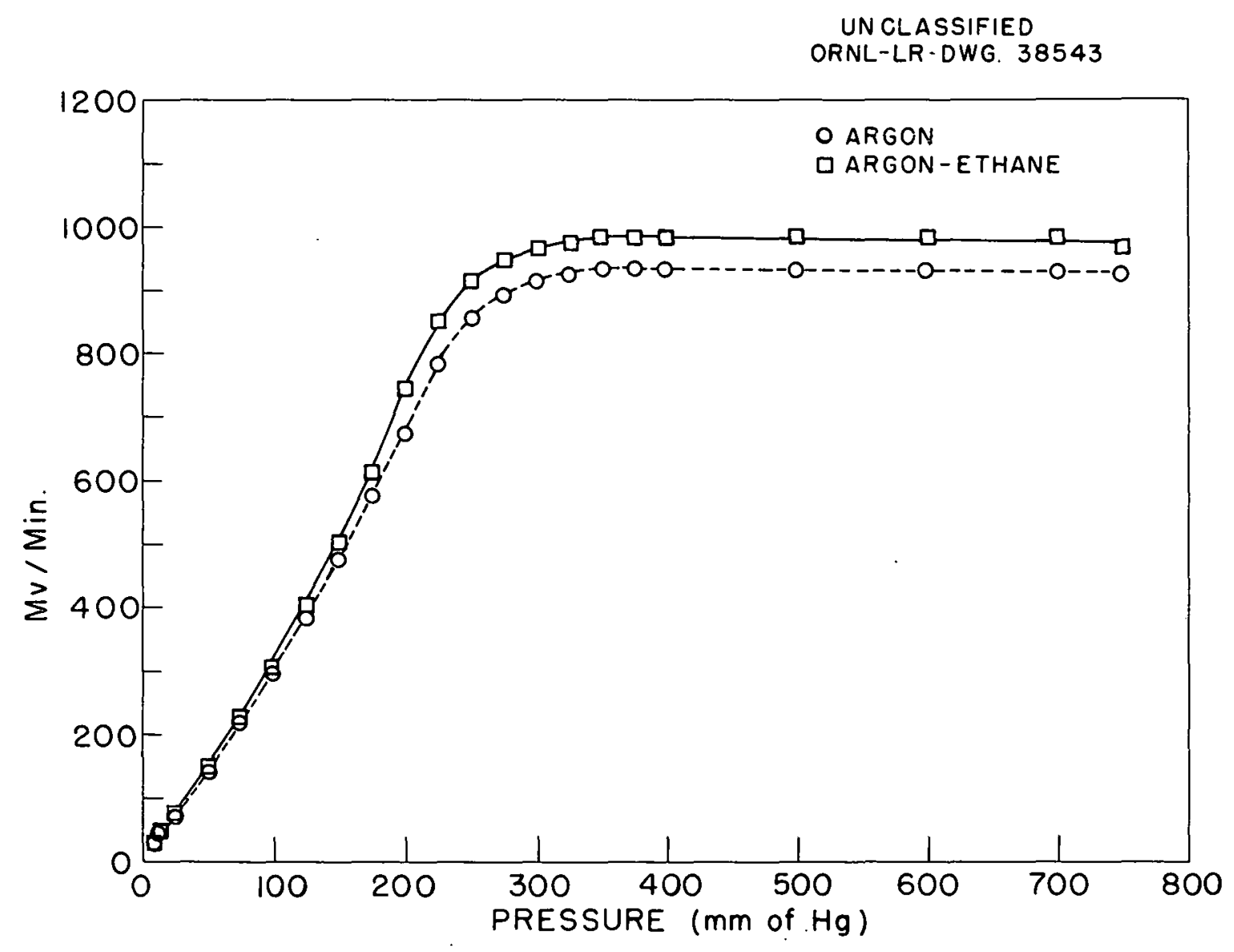

FIG. 7. IONIZATION VERSUS PRESSURE OF ARGON AND $99 \%$ ARGON-I\% ETHANE MIXTURE 


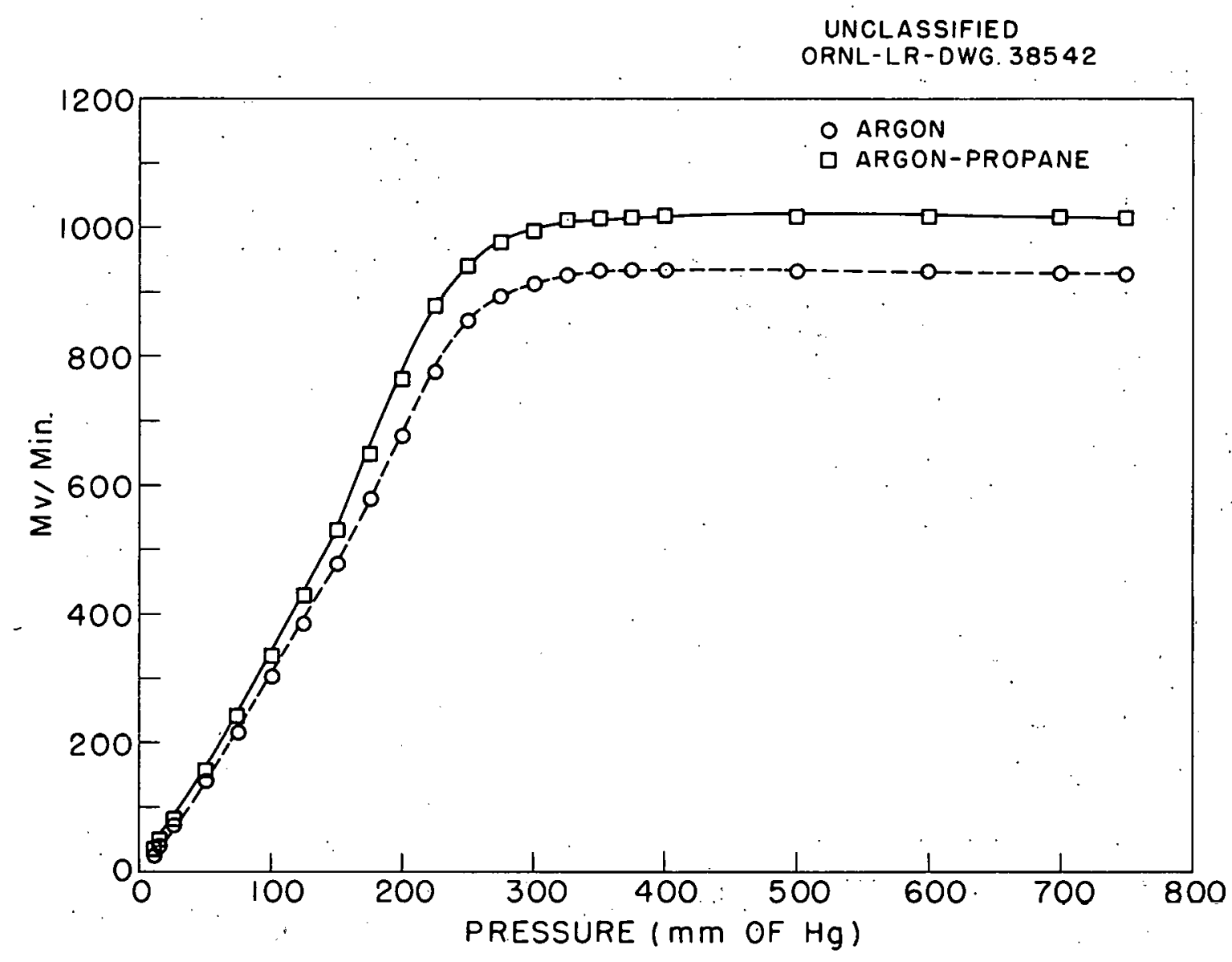

FIG. 8. IONIZATION VERSUS PRESSURE OF ARGON AND $97 \%$ ARGON-3\% PROPANE MIXTURE 
UNCLASSIFIED

ORNL - LR - DWG. 38541

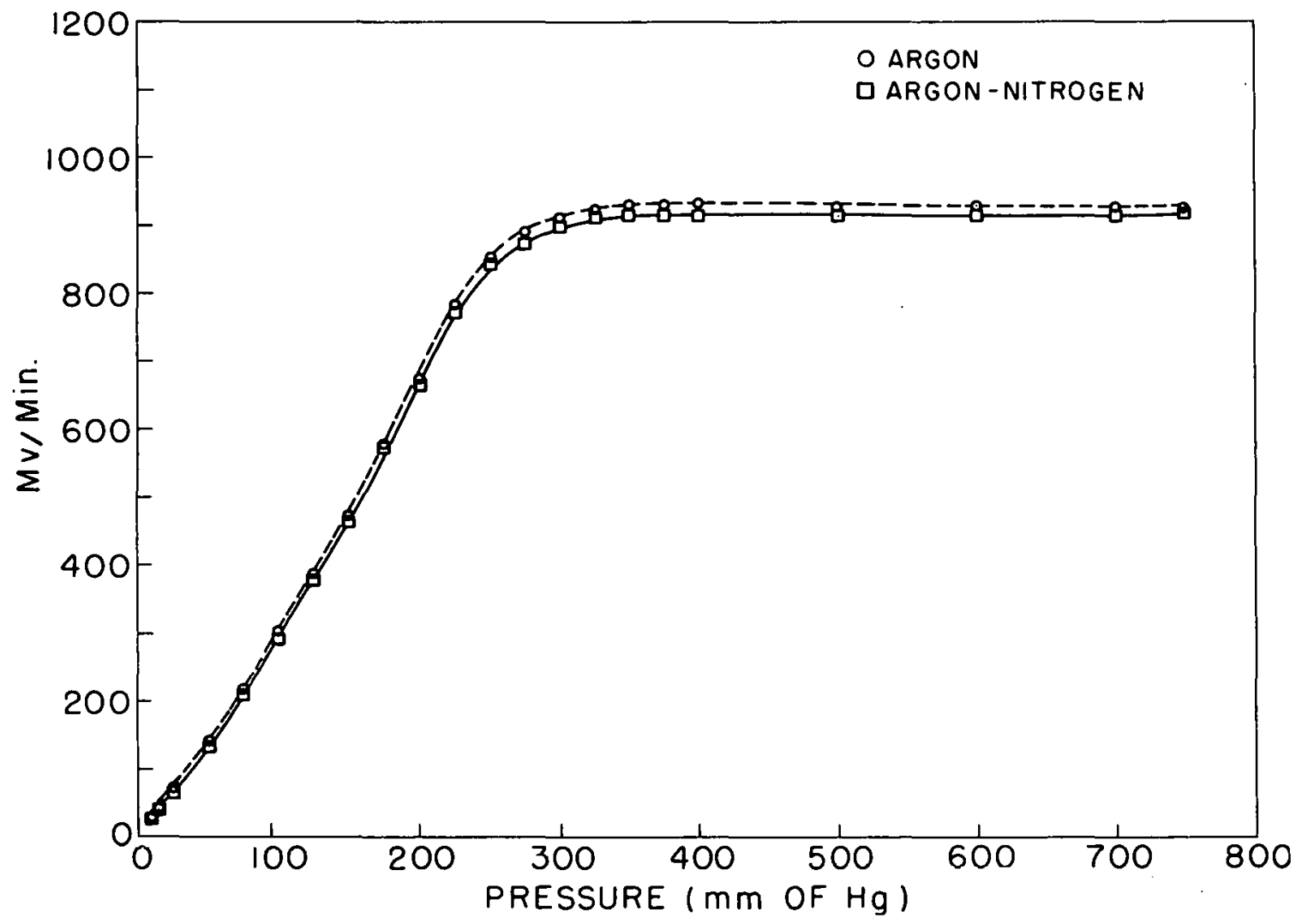

FIG. 9. IONIZATION VERSUS PRESSURE OF ARGON AND $97 \%$ ARGON-3\% NITROGEN MIXTURE 


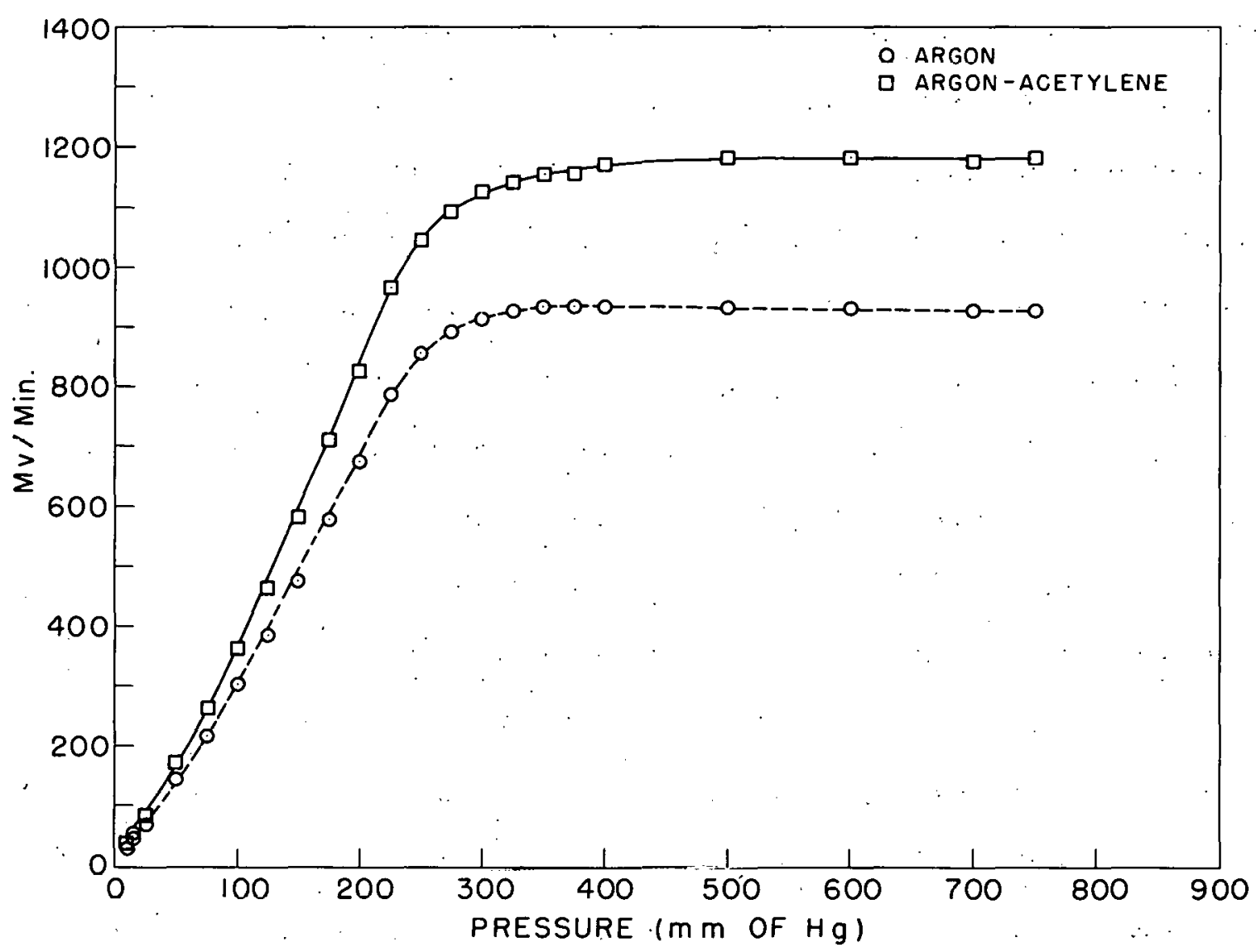

FIG. 10. 1ONIZATION VERSUS PRESSURE OF ARGON AND $99.5 \%$ ARGON-.5\% ACETYLENE MIXTURE 
$(15.5 \mathrm{l} \mathrm{ev})$ is above that of ethane.

Differentiating the curve in Fig. 6 with respect to pressure (Fig. 11) shows the similarity of curve shape for pure argon and the argonethane mixture since differential curves emphasize differences in the slopes of integral curves. This similarity of shape is maintained as the pressure is lowered until the range of the alpha particles equals the distance to the boundary of the sensitive volume of the ionization chamber. This pressure is slightly lower for the argon-ethane mixture than for pure argon because the mass stopping power of ethane is greater than that of argon. The similarity of the shapes of the ionization versus pressure curves shows that the magnitude of the increased ionization effect is not dependent on total pressure.

The errors introduced by starting and stopping the stop watch which was used to measure the time required to charge the capacitor were less than $\pm 0.21 \%$, and the errors in the percentage of impurity were not greater than $\pm 0.08 \%$. Errors were most signiflcant in the argonacetylene mixture in which $W$ changes the most rapidly as a function of percentage of impurity. ${ }^{2}$ The maximum errors introduced by variations in mixing were $\pm 0.68 \%$ for the argon-acetylene mixture and $\pm 0.04 \%$ for the other mixtures. Deviations in filling pressure were most important at pressures below that at which the range of the alpha particles is equal to the shortest path from the alpha source to the boundary of the sensitive volume of the ionization chamber. The absolute error in reading a pressure gauge remains constant throughout its range, however 


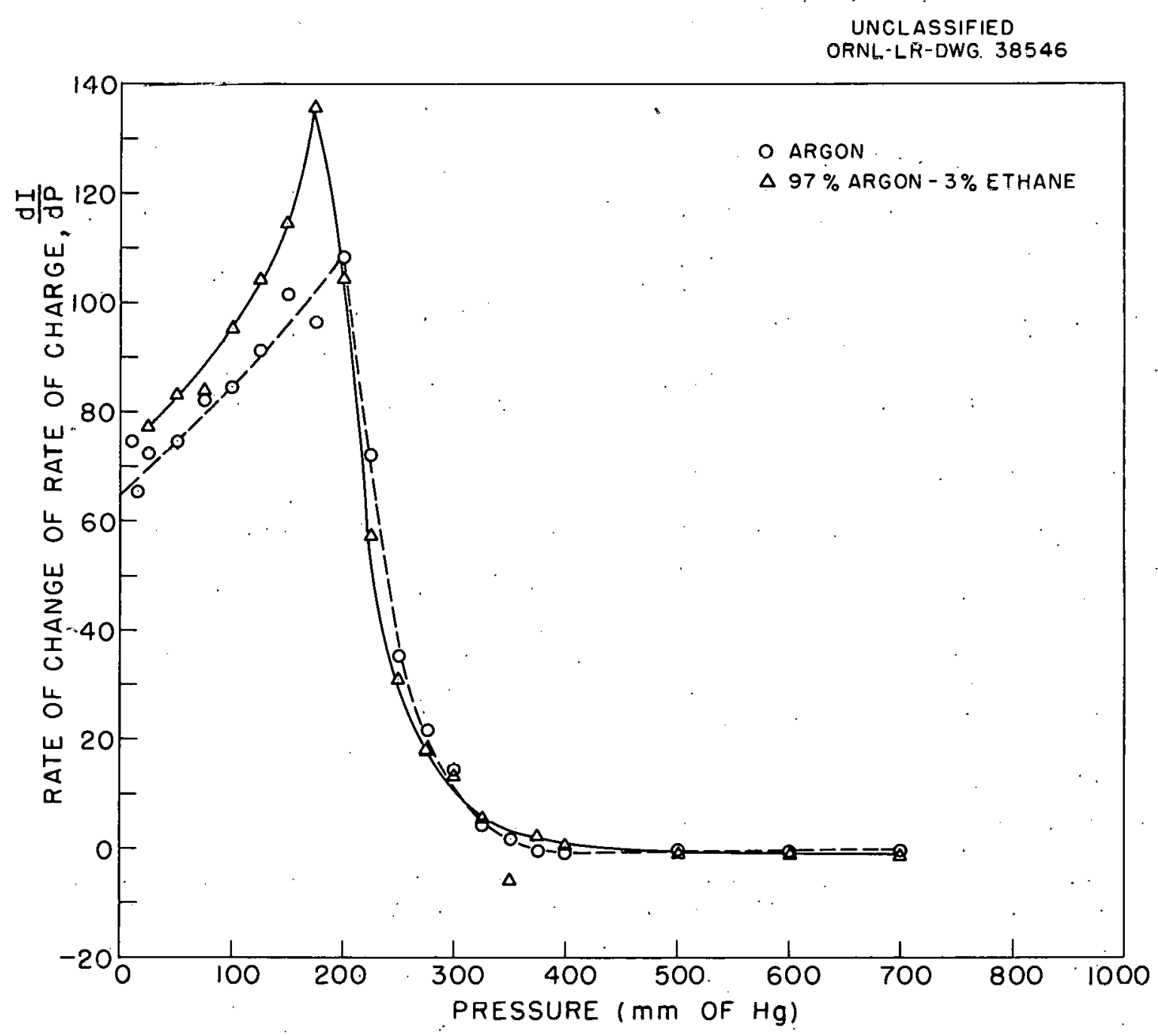

FIG. 11. RATE OF CHANGE OF RATE OF CHARGE VERSUS PRESSURE FOR ARGON AND $97 \%$ ARGON-3\% ETHANE MIXTURE 
the relative error changes as a function of pressure. For convenience the gas pressures used were divided into four ranges and a maximum relative error was calculated for each range. Total errors are shown in Table 111.

\section{Data from the Spectrum Study}

In the spectrographic study, ethane was the impurity of principal concern because its ionization potential lies above the metastable level of argon and below the 14.5 to $15.5 \mathrm{ev}$ energy level range under consideration. For this reason the argon-ethane data were of greater interest than those for other impurities.

A comparison of the microphotometer tapes for pure argon and $97 \%$ argon-3\% ethane mixture showed a significant reduction in the film densities for some of the spectral lines of argon in the mixture. This reduction, due to the addition of the ethane, ranged from 0.0 to 0.7 . Several lines were of exactly the same density as for pure argon. Table IV lists the effect of the ethane addition on thirty-eight lines.

A comparison of the argon-nitrogen spectrum with the pure argon spectrum showed no significant reduction of any of the argon lines. There were, however, nitrogen lines added to the spectrum. The argonpropane and argon-acetylene spectra showed a general reduction of intensity for all argon lines. The ionization potentials of both acetylene and propane are lower than the lowest excitation potential of argon. Therefore, the addition of acetylene or propane should decrease the intensity of all argon lines. 
Table ll

Total Relative Error of Data for Various Gases and Pressures

\begin{tabular}{|c|c|c|c|c|}
\hline \multirow{2}{*}{ Gas } & \multicolumn{4}{|c|}{ Pressure in $\mathrm{mm}$ of $\mathrm{Hg}$} \\
\hline & $p>300$ & $300>p>200$ & $200>p>100$ & $100>$ p. $>0$ \\
\hline Argon & $0.21 \%$ & $0.33 \%$ & $0.32 \%$ & $0.49 \%$ \\
\hline Argon-Ethane & $0.25 \%$ & $0.37 \%$ & $0.36 \%$ & $0.53 \%$ \\
\hline Argon-Propane & $0.25 \%$ & $0.37 \%$ & $0.36 \%$ & $0.53 \%$ \\
\hline Argon-Ni trogen & $0.25 \%$ & $0.37 \%$ & $0.36 \%$ & $0.53 \%$ \\
\hline Argon-Acetylene & $0.89 \%$ & $1.01 \%$ & $1.00 \%$ & $1.17 \%$ \\
\hline
\end{tabular}


Table IV

Effect on the Film Density of Several Lines of the Emission Spectrum of Argon by the Addition of $3 \%$ Ethane

\begin{tabular}{cccc} 
Wave Length & Transition & Upper & Upper \\
$\left(A^{\circ}\right)$ & Energy Level & Energy Level \\
$\left(\mathrm{cm}^{-1}\right)$ & $($ ev $)$ \\
\hline
\end{tabular}

Reduction to 0.3

$\begin{array}{llll}5698.64 & 2 p_{6}-6 d_{3} & 123808.60 & 15.366 \\ 5581.83 & 2 p_{9}-5 s_{1}^{11} & 123372.987 & 15.311 \\ 5073.08 & 2 p_{10}-5 s_{1}^{1} & 123815.53 & 15.366 \\ 5062.72 & 2 p_{6}-9 s_{4} & 125984.35 & 15.636 \\ 5032.02 & 2 p_{9}-7 s_{5} & 125329.99 & 15.554 \\ 5017.25 & 2 p_{6}-11 d_{1}^{\prime} & 126163.24 & 15.658 \\ 4804.33 & 2 p_{8}-13 d_{4} & 126426.07 & 15.690 \\ 4798.74 & 2 p_{9}-12 d_{4}^{3} & 126295.79 & 15.674\end{array}$

Reduction to 0.4

$\begin{array}{llll}5118.20 & 2 p_{8}-6 s_{1}^{1 !} & 125150.00 & 15.532 \\ 5048.81 & 2 p_{10}-5 s_{5} & 123903.295 & 15.377 \\ 4846.73 & 2 p_{9}-7 s_{1}^{11} & 126089.56 & 15.649 \\ 4768.67 & 2 p_{10}=6 s_{1}^{1 !} & 125066.501 & 15.522 \\ 3606.52 & 1 s_{4}-4 p_{5} & 121470.304 & 15.117\end{array}$


Table IV (continued)

Effect on the Film Density of Several Lines of the Emission Spectrum of Argon by the Addition of $3 \%$ Ethane

\begin{tabular}{|c|c|c|c|c|}
\hline $\begin{array}{c}\text { Wave Length } \\
\qquad\left(A^{\circ}\right)\end{array}$ & Trans & sition & $\begin{array}{c}\text { Upper } \\
\text { Energy Level } \\
\left(\mathrm{cm}^{-1}\right)\end{array}$ & $\begin{array}{c}\text { Upper } \\
\text { Energy Level } \\
\text { (ev) }\end{array}$ \\
\hline \multicolumn{5}{|c|}{ Reduction to 0.5} \\
\hline 6307.66 & $2 p_{6}$ & $-5 d_{3}$ & 122086.974 & 15.152 \\
\hline 5882.08 & ${ }^{2 p_{10}}$ & $-3 s_{3}$ & 121096.67 & 15.029 \\
\hline 3783.52 & $2 \mathrm{p}_{7}$ & $-5 s_{1}^{\prime \prime}$ & 123372.987 & 15.311 \\
\hline 5774.00 & $2 p_{3}$ & $-7: d_{3}$ & 124603.957 & 15.464 \\
\hline 5700.86 & $2 p_{6}$ & $-6 d_{4}$ & 123773.920 & 15.361 \\
\hline 5506.11 & ${ }^{2} p_{8}$ & $-6 d_{4}$ & 123773.920 & 15.361 \\
\hline 5241.10 & $2 p_{8}$ & $-7 d_{1}^{1 i}$ & 124692.02 & 15.475 \\
\hline 5219.30 & ${ }^{2} p_{8}$ & $-6 s_{5}$ & 124771.67 & 15.485 \\
\hline 4969.88 & $2 p_{7}$ & $-6 s_{3}$ & 126202.82 & 15.663 \\
\hline 4956.75 & $2 p_{9}$ & $-9 d_{4}^{\prime}$ & 125631.69 & 15.592 \\
\hline 4589.29 & $\mathrm{ls}_{2}$ & $-3 p_{6}$ & 117183.654 & 14.543 \\
\hline \multirow[t]{3}{*}{3398.75} & $\mathrm{ls}_{2}$ & $-7 \times x\}$ & 124857.27 & 15.495 \\
\hline & $1 s_{5}$ & & 124643.54 & 15.587 \\
\hline & \multicolumn{3}{|c|}{ Reduction to 0.7} & \\
\hline 3670.64 & $\mathrm{ls}_{2}$ & $-4 p_{3}$ & 122635.128 & 15.20 \\
\hline 3563.26 & $1 s_{3}$ & $-4 p_{2}$ & 122601.290 & 15.20 \\
\hline
\end{tabular}


Table IV (continued)

Effect on the Film Density of Several Lines of the Emission Spectrum of Argon by the Addition of $3 \%$ Ethane

\begin{tabular}{|c|c|c|c|}
\hline $\begin{array}{l}\text { Wave Length } \\
\qquad\left(A^{\circ}\right)\end{array}$ & Transition & $\begin{array}{c}\text { Upper } \\
\text { Energy Level } \\
\left(\mathrm{cm}^{-1}\right)\end{array}$ & $\begin{array}{c}\text { Upper } \\
\text { Energy Level } \\
\text { (ev) }\end{array}$ \\
\hline \multicolumn{4}{|c|}{ Reduction to 0.9} \\
\hline 7107.496 & $2 p_{8}-3 s_{5}$ & 119683.113 & 14.83 \\
\hline 6105.639 & $2 p_{4}-5 s_{1}^{i}, 1$ & 123505.536 & 15.31 \\
\hline 6145.43 & $2 p_{3}-5 s_{1}^{11}$ & 123557.459 & 15.32 \\
\hline \multirow[t]{2}{*}{6155.23} & $\left(2 p_{6}-4 s_{4}\right)$ & 122479.459 & 15.18 \\
\hline & $\left\{2 p_{4}-5 s s_{1}^{1}\right\}$ & 123372.987 & 15.29 \\
\hline 6098.807 & $2 p_{7}-4 s_{4}$ & 122479.459 & 15.18 \\
\hline \multicolumn{4}{|c|}{ No Reduction } \\
\hline 3632.684 & $1 s_{4}-4 p_{6}$ & 121270.682 & 15.03 \\
\hline 3559.3061 & $1 s_{5}-4 p_{6}$ & 121270.682 & 15.03 \\
\hline 3567.6565 & $1 s_{5}-4 p_{2}$ & 121165.431 & 15.02 \\
\hline 7206.986 & $2 p_{3}-3 s_{2}$ & 121161.356 & 15.02 \\
\hline 6170.183 & $2 p_{6}-4 s_{5}$ & 122440.109 & 15.18 \\
\hline 3635.54 & $2 p_{7}-6 d_{1}^{1}$ & 123826.85 & 15.35 \\
\hline
\end{tabular}


For all gas mixtures the film densities were repeated very accurately by a second determination. 


\section{DISCUSSION}

The increase of ionization due to the addition of an impurity to argon might be explained by the existence of a metastable state in argon at an energy level between 14.5 and $15.5 \mathrm{ev}$, the energy range in which the increased ionization effect disappears. Electrons in a metastable level can be released in the following ways: (a) the energy might be used in the ionization by collision of another gas: (b) the collision of two metastable atoms might produce an ion pair $(c)$ the metastable atom or molecule might be excited to a higher level and radiate a photon; (d) it might diffuse to the walls of the container: or (e) an electron transition accompanied by the emission of a photon might occur. Process (a) would contribute to the increase of ionization by the addition of a proper impurity. Processes (b), (c), (d), and (e) would be affected little, if at all, by the impurity addition. However, there are no excited levels of atomic argon above the known metastable levels for which the selection rules prohibit optical transitions. ${ }^{7}$ There are, therefore, no metastable excited states of atomic argon in the energy range under consideration. The constancy of the relative ion current during large pressure changes indicates that metastable argon molecules do not contribute to the increased ionization for argon-impurity mixtures because the concentration of molecular argon would be pressure dependent. Therefore, the mechanism must not depend upon an additional metastable level, atomic or molecular. 
The suggestion that the additional ionization effect is due to. Ionization of the impurity by subexcitation electrons was examined in the following manner: subexcitation electrons in argon by definition must have kinetic energies less than $11.5 \mathrm{ev}$, the lowest excited level of argon. According to theory, these electrons would be capable of ionizing impurities whose ionization potentials were equal to or less than the energy of the electrons. : The increased ionization effect has been shown to take place due to the addition of impuritles with ionization potentials ranging up to $14.5 \mathrm{ev}$. Therefore, the effect could not be due to subexcitation electrons alone.

The number of ions formed in a gas by electrons depends on the number of electrons which have energy equal to or exceeding the ionization potential of the gas. In an ionization chamber the energy distribution of electrons is a function of $E / P$. The energy of the peak population is altered by changing E/P, and the whole energy distribution is shifted correspondingly. The mean energy, $\epsilon$, of the population can be calculated ${ }^{8}$ by the formula,

$$
\epsilon=0.04 \times \mathrm{k}
$$

where $k$, the mean energy of agitation of an electron in terms of the mean energy of agitation of a molecule of argon at $15^{\circ} \mathrm{C}$, is a function of E/P and is tabulated from experimental data. Increasing $E / P$ from 0.00948 to

8 J. S. Townsend and V. A. Bailey, Phil. Mag。 44, 1033 (1922). 
0.718 ( $k=67$ to 241 , respectively) would shift $\epsilon$ from $2.68 \mathrm{ev}$ to $9.64 \mathrm{ev}$. This would not shift the mean energy of the population to an energy greater than the ionization potential of ethane $(12.8 \mathrm{v})$, but it would definitely increase the number of electrons with sufficient energy to ionize ethane

If electrons were contributing significantly to the added ionization a shift of $E / P$ through this range would have caused marked changes in the total amount of ionization, but the total ionization remained constant through this range of E/P. Therefore, agitation electrons, like subexcitation electrons, cannot contribute significantly to the extra ionization effect.

A relatively long lived excited state which is not metastable would have the same possibilities for loss of energy as a metastable state. The increased ionization effect studied was shown to be pressure independent but impurity dependent. Processes (b) and (d) would be independent of the presence of impurities and would be pressure dependent. Process (e) in itself would be impurity and pressure independent but might accompany processes (a) and (c).

If we consider process (a),

$$
A^{*}+x \rightarrow A+x^{+}+e^{-}
$$

the rate at which long lived excited argon atoms, $A^{*}$, would be discharged would depend on some constant, $C_{1}$, on the pressure of the impurity, $P_{x}$, 
and on the number of long lived excited argon atoms present, $N$.

$$
\left(\frac{d N}{d t}\right)_{1}=-C_{1} P_{x} N
$$

Similarly, for process (c),

$$
A^{*}+A \rightarrow A+A+h \nu
$$

the rate of excited argon discharge depends on some constant, $C_{2}$, the pressure of argon, $P_{a}$, and on the number of long lived excited argon atoms present.

$$
\left(\frac{d N}{d t}\right)_{2}=-C_{2} P_{a} N
$$

Process (e):

$$
A^{*} \rightarrow A+h \nu
$$

would depend only on the decay constant of the excited argon atoms, $\lambda$, and on the number of long lived excited argon atoms present, $N$.

$$
\left(\frac{d N}{d t}\right)_{3}=-\lambda N
$$

For these processes,

$$
\frac{d N}{d t}=\left(\frac{d N}{d t}\right)_{1}+\left(\frac{d N}{d t}\right)_{2}+\left(\frac{d N}{d t}\right)_{3}
$$


Substituting from Eqs. (14), (15), and (16),

$$
\frac{d N}{d t}=-C_{1} P_{x} N-C_{2} P_{a} N-\lambda N
$$

On rearranging,

$$
\frac{d N}{N}=-\left(c_{1} P_{x}+c_{2} P_{a}+\lambda\right) d t
$$

Integrating both sides gives

$$
\ln N=-\left(c_{1} P_{x}+c_{2} P_{a}+\lambda\right) t+k
$$

where $k$ is a constant of integration.

$$
N=N_{0} e^{-\left(C_{1} P_{x}+C_{2} P_{a}+\lambda\right) t}
$$

where $N_{0}$, a constant, is the number of long lived excited argon atoms at time $=0$.

Substituting into Eq. (14) gives

$$
\left(\frac{d N}{d t}\right)_{1}=-C_{1} P_{x} N_{0} e^{-\left(C_{1} P_{x}+C_{2} P_{a}+\lambda\right) t}
$$

or

$$
d N_{1}=-C_{1} P_{x} N_{0} e^{-\left(C_{1} P_{x}+C_{2} P_{a}+\lambda\right) t} d t
$$


Integrating both sides,

$$
N_{1}=-C_{1} P_{x} N_{0} \cdot \int_{0}^{\infty} e^{-\left(C_{1} P_{x}+C_{2} P_{a}+\lambda\right) t} \cdot d t
$$

Evaluating the integral,

$$
N_{1}=\frac{C_{1} P_{x}}{C_{1} P_{x}+C_{2} P_{a}+\lambda_{i}} \cdot O
$$

Since total pressure, $P$, is the sum of the partial pressures,

$$
P=P_{x}+P_{a}
$$

the partial pressure may be considered to be a certain fraction, $f$, of the total pressure,

$$
\begin{aligned}
& P_{x}=f_{1} P \\
& P_{a}=f_{2} P
\end{aligned}
$$

Substituting in Eq. (25),

$N_{1}=\frac{C_{1} f_{1} P}{C_{1} f_{1} P+C_{2} f_{2} P+\lambda} N_{0}=\frac{P C_{1} f_{1}}{P\left(C_{1} f_{1}+C_{2} f_{2}+\lambda / P\right)} N_{0}=\frac{C_{1} f_{1}}{C_{1} f_{1}+C_{2} f_{2}+\lambda / P} N_{0}$ 
It is thus seen that a competition between ionizing collisions with impurities and photon emission following argon-argon collisions can exist which, except for the term $\lambda / P$ in the denominator, is not dependent upon total pressure, but only upon the percentage of impurity present. During the course of ionization chamber experiments, ionization was found to remain constant while composition of the gas mixture was held constant and total pressure was varied.

Since experimental results require ionization to be independent of pressure, $\lambda / P$ will be assumed to be small compared to $c_{1} f_{1}+c_{2} f_{2}$. This assumption will be examined later. Equation (29) can now be written

$$
N_{1}=\frac{c_{1} f_{1}}{c_{1} f_{1}+c_{2} f_{2}} N_{0}
$$

Bortner and Hurst ${ }^{9}$ have shown that a formula for the value of $w$ of gas mixtures may be written as follows,

$$
\frac{1}{w_{m}}=\left(\frac{1}{w_{1}}-\frac{1}{w_{2}}\right) z+\frac{1}{w_{2}}
$$

where

$$
z=\frac{P_{1}}{P_{1}+a_{12} P_{2}}
$$

9 T. E. Bortner and G. S. Hurst, Phys. Rev. 93, 1236 (1954). 
and $a_{12}$ is an empirical constant.

If, as before we let

$$
f_{1} P=P_{1}
$$

and

$$
f_{2} P=P_{2}
$$

then

$$
z=\frac{f_{1}}{f_{1}+a_{12} f_{2}}
$$

Thus $z$ is not dependent on pressure but upon composition of the mixture. If this formula were applied to an argon-impurity mixture, it would fail because the one component of the mixture contributes to the ionization of the other. It is necessaby to add a correction to account for the extra ionization of the impurity by the excited argon. From Eq. (30), $N_{1}$, the number of long lived excited argon atoms which will undergo process (a), $A^{* *}+x \rightarrow A+x^{+}+e^{-}$, is

$$
N_{1}=N_{0} \frac{c_{1} f_{1}}{c_{1} f_{1}+c_{2} f_{2}}
$$

This can be rewritten as

$$
N_{1}=N_{0} \frac{f_{1}}{f_{1}+\left(c_{2} / c_{1}\right) f_{2}}
$$


Set

$$
\frac{f_{1}}{f_{1}+\left(c_{2} / c_{1}\right) f_{2}}=Y
$$

and let $\alpha$ be a quantity proportional to $N_{0}$. The term $\alpha Y$ was selected to be added to Eq. (31) for the following reasons:

1) the magnitude of the extra ionization effect must have a relationship to the number of excited argon atoms,

2) the effect must be independent of total pressure,

3) the correction term should allow the competition between ionization and collision induced photon emission, and

4) it is reasonable to assume that this correction term might have the same general form as $z$.

The addition of $\alpha Y$ to Eq. (31) gives

$$
\frac{1}{W_{m}}=\left(\frac{1}{W_{1}}-\frac{1}{W_{2}}\right) z+\frac{1}{W_{2}}+\alpha Y
$$

This implies that the extra ionization would increase monotonically as $f_{1}$, the fraction of impurity, increases to 1 . This cannot be true, for, as $f_{1}$ increases, the number of argon atoms available to form the long lived excited atoms, $A^{*}$, would decrease to 0 .

To account for the decrease in the availability of argon, the factor $(1-z)$ was introduced. The factor $(1-z)$ was selected because 
the term $z$ had already been used to describe the effect of the change of composition of the gas, and $(1-z)$ goes to 0 as the fraction of argon goes to 0 . The result is the corrected formula,

$$
\frac{1}{w_{m}}=\left[\left(\frac{1}{w_{1}}-\frac{1}{w_{2}}\right) z+\frac{1}{w_{2}}\right]+\alpha Y(1-z)
$$

The solid line in Fig. 12 is a plot of Melton's data for the value of $W$, for a mixture of argon and ethane, as a function of the composition of the gas. The broken line is a plot of $W$ as a function of composition by use of Eq. (39). The values of $a_{12}=2.13 \times 10^{-1},\left(C_{2} / C_{1}\right)=4.0 \times 10^{-3}$, and $\alpha=4.1 \times 10^{-4}$ were chosen to give the best fit.

The maximum deviation of the calculated curve from the experimental curve is $0.8 \%$. This is $0.3 \%$ greater than the probable experimental error. The accuracy of the value of $W$, calculated from this relatively simple formula, lends strong support to the theory of two competing processes, ionization versus photon emission.

The assumption that the term $\lambda / P$ in Eq. (29) is not significant can now be examined more fully. If $\lambda / P$ were much smaller than $C_{1} f_{1}+C_{2} f_{2}$, the competition between ionization and photon emission following a collision would be independent of pressure. An equivalent condition is that in Eq. (25) $\lambda$ is much smaller than $C_{1} P_{x}+C_{2} P_{a}$. A probable maximum value for $C_{1} P_{x}+C_{2} P_{a}$ can be calculated. 
UNCLASSIFIED

ORNL-LR-DWG. 38540

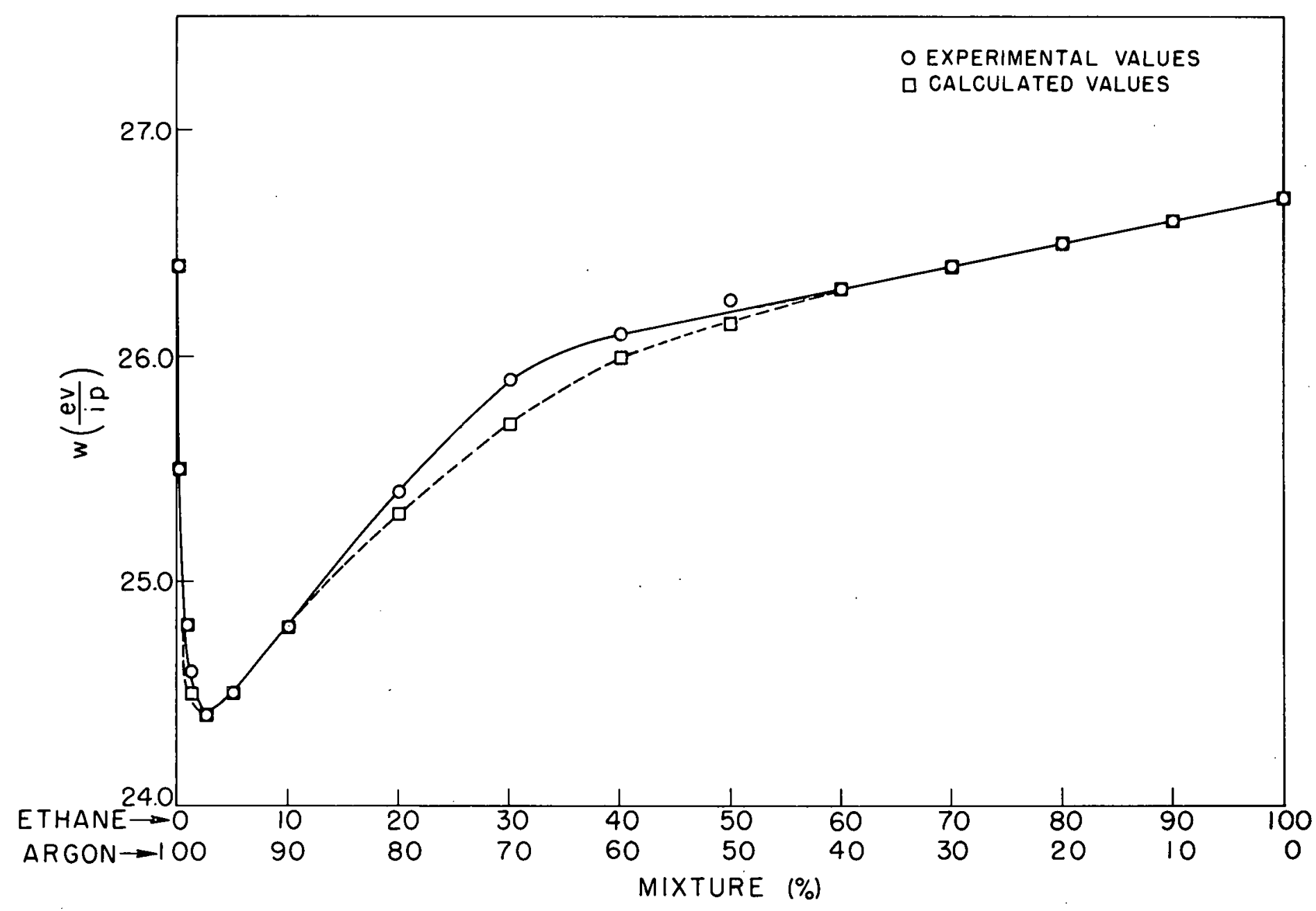

FIG. 12. CALCULATED AND EXPERIMENTAL VALUES OF W AS A FUNCTION OF GAS COMPOSITION 


$$
\left(\frac{d N}{d t}\right)_{1}=-\sigma N \underline{n}_{\underline{x}} \bar{v}
$$

where

$\sigma$ is the cross section for ionization in process (a) in $\mathrm{cm}^{2}$, $\frac{n_{x}}{\bar{v}}$ is the number of molecules of impurity per $\mathrm{cm}^{3}$,
$\bar{v}$ is the velocity of the molecules and atoms in $\mathrm{cm} \mathrm{sec}^{-1}$, and $\mathrm{N}$ is the number of excited argon atoms:

Using Eq: (14),

$$
-C_{1} P_{x} N=-\sigma \underline{n}_{\underline{x}} \bar{v}
$$

or

$$
c_{1} P_{x}=\sigma \underline{n_{x}} \bar{v}
$$

A maximum value for $\sigma$ may be obtained by taking the gas kinetic cross section, i.e. about $10^{-16} \mathrm{~cm}^{2}$. The velocity, $\bar{v}$, is about $5 \times 10^{4} \mathrm{~cm} \cdot \mathrm{sec}^{-1}$. In a mixture of $97 \%$ argon. and $3 \%$.ethane, for example, wi th a total pressure of $750 \mathrm{~mm} \mathrm{Hg}, \underline{\mathrm{n}_{x}}$ would equal $7.5 \times 10^{17}$ molecules $\mathrm{cm}^{-3}$. From Eq. (42),

$$
c_{1} P_{X}=3.75 \times 10^{6} \sec ^{-1}
$$

Using the value $4.0 \times 10^{-3}$ for the ratio $C_{2} / C_{1}$ obtained by the curve fitting procedures, the value of $C_{2} P_{a}$ is seen to be 


$$
\begin{gathered}
C_{2} P_{a}=4.86 \times 10^{5} \mathrm{sec}^{-1} \\
C_{1} P_{x}+C_{2} P_{a}=4.2 \times 10^{6} \mathrm{sec}^{-1}
\end{gathered}
$$

Therefore, if $\lambda$ is much less than $4.2 \times 10^{6} \mathrm{sec}^{-1}$, the natural lifetime of the excited state of argon,

$$
\tau=1 / \lambda
$$

is much greater than $2.4 \times 10^{-7} \mathrm{sec}$. If $\sigma$ were as small as $10^{-18} \mathrm{~cm}^{2}$, $\tau$ would have to be greater than $2.4 \times 10^{-5} \mathrm{sec}$.

Such a range of values for the lifetime would not be un reasonable especially if imprisonment were to take place, i.e. the energy of excitation could be transfersed by collision from one argon atom to another so that an argon atom in the excited state would exist although it would not be the identical argon atom. In this manner the energy causing the excited state would remain in argon for a longer time before dissipation. Meissner and Graffunder ${ }^{10}$ have reported half lifetimes of non-metastable excited argon atoms of up to $3.6 \times 10^{-3}$ seconds.

If by the addition of an impurity, an increase in ionization takes place, it follows that a significant fraction of the excited argon atoms which, in pure argon, would return to ground state through optical

10 K. W. Meissner and W. Graffunder, Ann. Physik 84, 1009 (1927). 
transitions will return to ground state through ionizing collisions with the impurlty. The consideration of this implication leads to the examination of the emission spectrum of argon and the changes in it caused by the addition of impurities. There might be a group of lines in the spectrum of excited argon corresponding to the transitions starting from the proposed long lived state, process (e), and from levels slightly above the long lived state, process (c). Competition from another process, (a), brought about by the addition of an impurity to the argon would allow a smaller number of excited argon atoms to undergo the transitions in (c), and (e). Therefore, these spectral lines would be less intense in the presence of an impurity which could be ionized by argon atoms in a long lived excited state. There would, of course, be additional lines in the mixture spectrum due to excited atoms or molecules of the impurity.

The detection of 25 lines of the argon spectrum for which the film density was reduced to 0.5 or less by the addition of an impurity, ethane, is significant evidence of the existence of the proposed competition between ionization and optical transitions. Since this competition depends on an excited state of atomic argon with a lifetime long. enough to permit ionizing collisions with impurity atoms or molecules, the reduced film density of the argon spectral lines strongly indicates the existence of such a state. 


\section{CONCLUSION}

The existence of one or more long lived non-metastable excited states of argon in the 15 to $15.5 \mathrm{ev}$ range has been indicated. The increased ionization observed when certain impurities are added to argon is attributed to this long lived excited state rather than to molecular argon or subexcitation electrons. A competitive process between optical decay and ionizing collisions was evidenced by spectral analysis of the gas mixtures. From these experiments it was not possible to determine the exact energy levels of the suggested long lived excited states. Valuable additional information could be gained by performing a spectrographic study of the effects of the addition to argon of several. Impurities using alpha particles instead of electric sparks as a source of excitation. This study should include observation of lines in at least part of the ultraviolet region and in the infrared region as well as in the visible region. 


\section{B IBLIOGRAPHY}

Bortner, T. E., and Hurst, G. S., "Energy Per Ion Pair for 5-Mev Alpha Particles," Phys. Rev。 90, 160, 1953.

Bortner, T. E., and Hurst, G. S., "lonization of Pure Gases and Mixtures of Gases by 5-Mev Alpha Particles," :Phys. Rev. 93, 1236, 1954. Green, J. B., and Fried, B.; "The Zeeman Effect in the Spectrum of Argon "' Phys. Rev. 54, 876, 1938.

Handbook of Chemistry and Physics, Chemical Rubber Publishing Co., Cleveland (1957-1958).

Meissner, K. W., "Die Serien des. Argonbogenspektrums. I," Zelt. Phys. 39, 172, 1926; "Die Serien des Argonspektrums. 11." Zeit. Phys. 40, 839, 1927.

Meissner; K.W., and Graffunder, W. "Über die Messung der Lebensdauer Angeregter Atomzustände," Ann. Physik 84, 1009, 1927.

Melton, C. E., 'Measurements of Ionization Produced by 5-Mev Alpha Particles in Argon Mixtures," A Thesis, Vanderbilt University, February 1954.

National Bureau of Standards Circular 467, "Atomic Energy Levels," U. S. Dept. of Commerce (1949).

Platzman, R. L., "Subexcitation Electrons," Rad. Res. 2, I0 1955.

Townsend, J. S., and Bailey, V. A., "The Motion of Electrons in Argon and in Hydrogen," Phil. Mag. 44, 1033, 1922. 


\section{THIS PAGE \\ WAS INTENTIONALLY \\ LEFT BLANK}




\author{
ORNL-2807 \\ Physics and Mathematics \\ TID-4500 (15th ed.)
}

\title{
INTERNAL DISTRIBUTION
}

1. C. E. Center

2. Biology Library

3. Health Physics Library

4-5. Central Research Library

6. Reactor Experimental Engineering Library

7-26. Laboratory Records Department

27. Laboratory. Records, ORNL R.C.

28. A. M. Weinberg

29. L. B. Emlet (K-25)

30. J. P. Murray ( $Y-12)$

31. J. A. Swartout

32. E. H. Taylor

33. E. D. Shipley

34. K. Z. Morgan

35. M. L. Nelson

36. W. H. Jordan

37. C. P. Keim

38. P. M. Reyling

39. R. S. Livingston

40. S. C. Lind

4I. F. I. Culler

42. A. H. Snell"

43. A. Hollaender

44. M. T. Kelley

45. T. A. Lincoln

46. A. S. Housèholder

47. C. S. Harrill

48. C. E. Winters

49. H. E. Seagrén

50. J. A. Lane:

51. E. E. Andêrson

52. D. Phillips

53. R. A. Charpie

54. C. E. Cliffórd

55. M. J. Skiñnër

56. R. R. Dickiśon

57. S. I. Auerbach

58. K. E. Cowser

59. L. B. Farabee

60. F. J. Daviŝs

61. R. J. Morton

62. C. E. Haymes

63. H. H. Hubbell, Jr.
64. E. G. Struxness

65. J. Neufeld

66. J. C. Hart

67. T. H. J. Burnett

68. G. S. Hurst

69. T. E. Bortner

70. D. M. Davis

71. P. E. Brown

72. E. D. Gupton

73. R. L. Clark

74. W. W. Ogg

75. E. J. Kuna

76. J.R. Muir

77. J. A. Auxier

78. M. F. Fair

79. G. W. Royster, Jr.

80. F. C. Maienschein

81. W. J. Boe'gley

82. F. I. Parker

83. B. R. Fish

84. M. B. Edwards

85. F. M. Empson

86. R. D. Birkhoff

87. R. H. Ritchie

88. J. A. Harter

89. J. S. Cheka

90. P. N. Hensley

91. E. B. Wagner

92. C. A. Preskitt

93. E. T. Arakawa

94. L. G. Epel

95. C. E. Melton

96-125. F. W. Sanders

126. J. L. Magee (consultant)

127. T. D. Strickler (consultant)

128. R. L. Platzman (consultant)

129. J. C. Frye (consultant)

130. W. H. Langham (consultant)

131. L. S. Taylor (consultant)

132. A. Wolman (consultant)

133. R. E. Zirkle (consultant)

134. ORNL - Y-12 Technical Library, Document Reference Section

\section{EXITERNAL DISTRIBUTION}

135. Division of Research and Development, AEC, ORO

136-745. Given distribution as shown in TID-4500 (15th ed.) under Physics and Mathematics category ( 75 copies - OTS) 